\title{
Clinical Decision Support Tools for Selecting Interventions for Patients with Disabling Musculoskeletal Disorders: A Scoping Review
}

\author{
Douglas P. Gross ${ }^{1}$ - Susan Armijo-Olivo ${ }^{2}$ - William S. Shaw ${ }^{3} \cdot K^{2}$ Klly Williams-Whitt ${ }^{4}$. \\ Nicola T. Shaw ${ }^{5}$ Jan Hartvigsen ${ }^{6,7} \cdot$ Ziling Qin $^{2} \cdot$ Christine Ha $^{2} \cdot$ Linda J. Woodhouse ${ }^{1}$. \\ Ivan A. Steenstra ${ }^{8}$
}

Published online: 14 December 2015

(C) Springer Science+Business Media New York 2015

\begin{abstract}
Purpose We aimed to identify and inventory clinical decision support (CDS) tools for helping front-line staff select interventions for patients with musculoskeletal (MSK) disorders. Methods We used Arksey and O'Malley's scoping review framework which progresses through five stages: (1) identifying the research question; (2) identifying relevant studies; (3) selecting studies for analysis; (4) charting the data; and (5) collating, summarizing and reporting results. We considered computer-based, and other available tools, such as algorithms, care pathways, rules and models. Since this research crosses multiple disciplines, we searched health care, computing science and business databases. Results Our search resulted in 4605
\end{abstract}

Douglas P. Gross

dgross@ualberta.ca

Ivan A. Steenstra

ivan.steenstra@ryerson.ca

1 Department of Physical Therapy, University of Alberta, 2-50 Corbett Hall, Edmonton, AB T6G 2G4, Canada

2 Faculty of Rehabilitation Medicine, University of Alberta, 3-62 Corbett Hall, Edmonton, AB T6G 2G4, Canada

3 Liberty Mutual Research Institute for Safety, 71 Frankland Road, Hopkinton, MA 01748, USA

4 University of Lethbridge, Calgary Campus, Suite S6032, 345 - 6th Avenue SE, Calgary, AB T2G 4V1, Canada

5 Algoma University, 1520 Queen Street East, CC 303, Sault Ste. Marie, ON P2A 2G4, Canada

6 University of Southern Denmark, Odense, Denmark

7 Center for Muscle and Joint Health, Nordic Institute of Chiropractic and Clinical Biomechanics, Campusvej 55, 5230 Odense M, Denmark

8 Institute for Work \& Health, 481 University Avenue, Suite 800, Toronto, ON M5G 2E9, Canada manuscripts. Titles and abstracts were screened for relevance. The reliability of the screening process was high with an average percentage of agreement of $92.3 \%$. Of the located articles, 123 were considered relevant. Within this literature, there were $43 \mathrm{CDS}$ tools located. These were classified into 3 main areas: computer-based tools/questionnaires $(\mathrm{n}=8,19 \%)$, treatment algorithms/models $(\mathrm{n}=14,33 \%)$, and clinical prediction rules/classification systems $(n=21,49 \%)$. Each of these areas and the associated evidence are described. The state of evidentiary support for CDS tools is still preliminary and lacks external validation, head-to-head comparisons, or evidence of generalizability across different populations and settings. Conclusions CDS tools, especially those employing rapidly advancing computer technologies, are under development and of potential interest to health care providers, case management organizations and funders of care. Based on the results of this scoping review, we conclude that these tools, models and systems should be subjected to further validation before they can be recommended for large-scale implementation for managing patients with MSK disorders.

Keywords Decision-making - Decision support techniques · Musculoskeletal - Back pain - Return to work · Sick leave

\section{Introduction}

Regional musculoskeletal (MSK) disorders, such as back, neck and shoulder pain, are some of the most common and disabling health conditions internationally, leading to substantial personal, social and economic burden [1, 2]. The high costs of disability and lost productive work time associated with these conditions demand significant 
improvements in health care strategies, especially in those aimed at helping patients return to work. Systematic reviews of health care interventions, such as physical conditioning or pain management programs, targeted to regional MSK disorders have indicated modest effectiveness [3-6]. Furthermore, the response of individual patients to these interventions is highly variable. Some patients benefit greatly, while others do not improve, or even experience a worsening of problems [7]. Improved methods for selecting the optimal interventions for individual patients (i.e. personalized rehabilitation) would be invaluable.

Clinical decision support (CDS) is a term that has been used to define the myriad of ways in which knowledge is represented in health information and/or management systems to assist health care providers and other stakeholders in patient management decisions [8]. CDS tools are devices, instruments, questionnaires or other diverse resources (including algorithms, continuums of care, and treatment models) that present knowledge to health care decision-makers, and are often designed as point-of-care resources that support decisions regarding optimal treatment choices. Research and development of CDS tools is a rapidly growing field. These tools are attractive options, given the widespread adoption of computer tablets and smart phones. Also, CDS tools can be an efficient and timesaving strategy for busy clinicians if treatment algorithms are evidence-based and present minimal risks. This technology has the potential to augment complex decisions such as those performed for regional MSK disorders. Computerized CDS has the potential to significantly improve human decisions by expediting information retrieval, identifying unique patient needs, triaging care, and matching patients to the most appropriate resources and treatments.

Some promising CDS tools have been developed specifically for use with patients that have regional pain disorders [9-11]. However, the effectiveness, utility and feasibility of CDS resources in the treatment of regional MSK disorders has been under investigated [12]. Previous systematic reviews of CDS tools have focused on the evaluation of medical management and included only randomized controlled trials from the health care literature [12-17]. However, CDS for the treatment of patients with regional MSK disorders is an emerging area that covers multiple disciplines (including health care, computing science, occupational health services and human resource management). The current literature is therefore diverse and fragmented [11, 18, 19] using inconsistent terminologies and methods. However, to date, no thorough synthesis and summary of these methods is available. In addition, the state of the science in terms of effectiveness, utility, and feasibility of CDS resources in the treatment of MSK disorders has not been summarized as a whole. Given the diversity of the literature and emerging nature of the field, a comprehensive scoping review is needed to map the scientific and grey literature on this topic [20].

The purpose of this project was therefore to conduct a scoping review of CDS tools designed to help decisionmakers select interventions that are specifically intended to improve function and return to work in patients with painrelated MSK disorders. This review was also open to other patient related outcomes such as pain, and disability. Our study aims were to identify and inventory CDS tools for helping front-line staff select interventions. We considered both computer-based CDS and other available tools such as treatment algorithms, care pathways, prediction rules, and models. In addition, we aimed to summarize key concepts and terminology to provide criteria for future reporting, evaluate and synthesize evidence of the effectiveness and utility of the available tools, and recommend directions for future research and development in this area.

\section{Methods}

\section{Design}

This study was a scoping review, which is a methodology for rigorously collecting, synthesizing, appraising and presenting findings from existing research on a topic [2022]. This approach is especially relevant when an area is emerging or diverse because it examines the extent, range and nature of the research activity [23]. Generally scoping reviews are referred to as 'a mapping process' since they summarize a range of evidence in order to convey the breadth and depth of a field [24]. Unlike systematic reviews, scoping reviews do not require appraisal of the quality of the included studies. However, the scoping process requires an analytical interpretation and inventory of the available literature. A scoping review is also useful for determining whether enough literature is available on a topic to conduct a formal systematic review or a metaanalysis or to identify gaps in the literature. In addition, scoping reviews can include a range of study designs and address complex and diverse questions that cannot typically be addressed with a systematic review. Our research area is both emerging and diverse. For these reasons, we chose to conduct a scoping review.

We adopted the scoping review framework proposed by Arksey and O'Malley [23]. This framework progresses through five stages: (1) identifying the research question; (2) identifying relevant studies; (3) selecting studies for analysis; (4) charting the data; and (5) collating, summarizing and reporting results. Each stage will be discussed in detail below. 


\section{Identifying the Research Question}

An iterative process was used in which we reflexively adapted our question, search terms, and strategy to ensure comprehensive coverage of the literature [23]. An initial question provided the scope for the review and contained several key concepts that guided the search terms used. However, the question was refined based on the broad spectrum of articles we obtained in the initial search. Initially we had included CDS tools for selecting interventions as well as making diagnoses and prognoses. However, due to the extensive breadth of the literature obtained and impracticality of reviewing all 3 research domains, we decided to focus on intervention tools only. This decision was made after consultation with all the researchers and knowledge users involved.

Our final research question was the following: "Do validated decision support tools (especially computerbased tools) exist for selecting appropriate interventions for improving function and return to work in patients with pain-related MSK disorders?"

\section{Identifying Relevant Studies}

Relevant studies were identified through online searches of health care, computing science and management databases. These searches were performed with the assistance of two experienced research librarians at the University of Alberta who had access to, and a thorough knowledge of all the necessary databases and search engines. Databases searched included Ovid MEDLINE, Ovid EMBASE, Scopus, CINAHL, Business Source Complete, ABI/INFORM Global, Social Science Research Network (SSRN), Web of Science, ACM Digital Library, IEEE Xplore, ACM Computing Reviews, Computing Research Repository (CoRR), NECI ResearchIndex (formerly CiteSeer) and Google Scholar. Our search strategies were adapted to the various databases as required with the assistance of the librarians. The search included all articles in all languages since the inception of the databases.

Keywords included musculoskeletal diseases; тиsсиloskeletal disorders; back pain; neck pain; shoulder pain; disability evaluation; vocational rehabilitation; return to work; decision support techniques; decision support tools; decision making; clinical protocols; computer-assisted. An example of a search strategy performed in Medline is presented in "Appendix 1".

Grey literature (unpublished documents from outside the peer-reviewed scientific literature) were also searched. We applied the Canadian Agency for Drugs and Technologies in Health's Grey Matters search tool to search for relevant information and websites [25]. In addition, Google was searched to identify possible unpublished studies. Relevant articles from the study teams' own research or libraries were also included.

Each CDS tool located was tracked in the Scopus database and Google Scholar to determine whether additional studies investigating the tool had been published.

\section{Selecting Studies for Analysis}

The following were the final set of inclusion/exclusion criteria for the review:

Topic of the article A CDS tool for selecting interventions.

Population Patients with any painful MSK disorder (e.g., regional pain disorders of the back, neck, knee, shoulder, etc.). Our review included all MSK conditions available in the literature and all terms referring to MSK conditions were included in the searches. We excluded articles on non-MSK disorders including metabolic/ endocrine disorders (i.e. osteoporosis, diabetic ulcers), rheumatic disorders (i.e. ankylosing spondylitis, rheumatoid arthritis, fibromyalgia) and other general medical conditions.

Outcome Functional and work-related outcomes, including return to work, disability, performance, and absenteeism. Functional recovery is a crucial outcome in regional pain disorders. From the perspective of the various stakeholders involved (i.e. workers, insurers, employers and health care providers), recovery from pain is important; however, functional recovery-such that the patient can return to work and participate in normal daily living-is equally important and has important career and quality-of-life implications [26, 27]. Functional recovery is also often easier to measure. For these reasons, we focused primarily on interventions aimed at improving function or facilitating return to work and other activities of daily living.

Study type Any design describing or evaluating a CDS tool. Systematic reviews were excluded but references within those located were searched for further articles.

The titles and abstracts of articles obtained from the online databases were reviewed and appraised for relevance. Two independent researchers from the team read each title/abstract and judged whether they were relevant to the research question. When there were disagreements between reviewers, the principal researcher (DPG) offered additional consultation until a decision could be reached. If the relevance of a study was still unclear, then the full article was obtained. After selecting the relevant abstracts and titles, two independent researchers assessed the corresponding full versions of the studies to determine which articles should be included in the full review. If disciplinespecific questions arose, the reviewers consulted with the 
team member with relevant expertise (i.e. computers, health care, human resource management, etc.) who could answer the question. We used a Microsoft Access (Redmond, Washington) database stored on an internal server at the University of Alberta that was securely accessible by team members for all stages of the review.

\section{Consultation with Knowledge Users}

The consultation process for this study incorporated the development of an advisory committee that included knowledge users who were representatives of local rehabilitation clinics in the Edmonton area, national networks of health care clinics that provide rehabilitation to injured workers, and experienced compensation case managers. We held meetings with knowledge users at two key stages of the review: selecting studies for analysis, and summarizing and reporting results. Knowledge users were asked whether they knew of any CDS tools currently in use or relevant articles. Feedback from knowledge users during these consultative meetings highlighted the importance of: (1) including functional and return-to-work outcomes as search terms; (2) considering not only papers describing specific CDS tools, but also theoretical or conceptual papers dealing with models or algorithms describing treatment selection approaches for patients with MSK disorders; (3) having reviewers consider workplace-based interventions (i.e. accommodations, modifications, etc.) and work-related outcomes (i.e. productivity, absenteeism, etc.) during abstract and title screening; and lastly, (4) considering the importance of feasibility, time of tool administration, cost, and ease of interpretation in addition to scientific validation when considering the utility of any CDS tools located. Before charting the data, the knowledge users were consulted to determine whether the number of articles selected was appropriate and whether the search terms should be altered.

\section{Data Analysis}

\section{Charting the Data}

Reviewers extracted relevant information from the articles and entered it into an electronic data chart created with the Microsoft Access program. This form included data for authors, year of publication, article title, discipline of the lead authors, geographic location of the study, type and brief description of the CDS tool (including a list of factors included in the tool's algorithm such as age, sex, pain level, etc.), cost of the tool, study population, study design and goals, methods used, outcome measures used, important results and any economic data recorded. For computerbased tools, we extracted additional information using categories taken from a previously published CDS taxonomy [28]. These charting methods provided a standard and systematic approach to summarize the papers and extract all relevant information.

\section{Collating, Summarizing and Reporting Results}

During this stage, we created an overview of all research located. Initially, we presented a basic numerical summary of the studies, including the extent, nature and distribution of the articles. Then, we summarized articles according to the types of tools described or evaluated, research methods used, populations studied, and study results/outcomes.

As mentioned earlier, the scoping review methodology was intended to summarize both the breadth and depth of the literature. We reported the number of articles for each CDS tool as well as some descriptive information about the articles. Since this was a scoping review, we did not undertake a critical appraisal of quality. However, we attempted to map the diversity observed and inventory the various study designs and methods used. This procedure allowed us to draw conclusions about the nature of research in this area and provide recommendations for future studies.

Several clinical prediction rules were designed to identify those individuals likely to respond positively to a particular treatment or intervention. These types of tools have been summarized in other reviews [29, 30], but we created an updated table to establish the range of tools in this category and to examine the strengths and limitations of these rules.

The various CDS tools identified in the articles were also categorized, and key concepts and terminology used in the articles were summarized in tables.

Guidelines developed by Terwee et al. [31] were used to define quality of measurement properties of the CDS tools. Briefly, quality of measurement included internal (internal consistency, relevance of items and representativeness of items of the scale-content validity) as well as external components of validity (the relationship with other tests in a manner that is consistent with theoretically derived hypotheses-construct validity). Intra and inter-rater reliability (i.e. repeatability of measurements taken by the same tester at different times and repeatability of measurements taken by different testers, respectively) were also considered. Definitions of psychometric properties for this review are provided in "Appendix 2".

\section{Results}

The initial search considering all online databases identified 4605 potentially relevant articles. From these, 189 unique studies were included for the second stage; 
screening full texts. After screening full texts, 133 articles were selected. From these, 34 articles were removed since they were systematic reviews or considered irrelevant for the purposes of the study. However, their references were searched. From the reference search of these studies and stakeholder meetings, we obtained 24 additional articles. Thus, 123 studies were included for data extraction. The reliability of the screening process of titles and abstracts was high with an average agreement percentage of $92.3 \%$ between reviewers. Figure 1 shows the flow chart of our article search and relevance selection process. A search of the grey literature obtained no new documents or websites specific to MSK disorders.

\section{General Description of Articles}

Of the 123 relevant articles located, most originated in North America $(\mathrm{n}=70,57 \%)$, were published between 2006 and $2014(\mathrm{n}=101,82 \%)$, and discussed a clinical prediction rule or a classification system $(\mathrm{n}=79,64 \%)$. Twenty-one articles (17\%) discussed treatment algorithms or models, 15 (12\%) discussed questionnaires, while only $8(7 \%)$ discussed computer-based tools. Most of the articles pertained to low back pain $(n=69,56 \%)$, followed by neck, shoulder or arm pain $(\mathrm{n}=21,17 \%)$, and general MSK disorders $(\mathrm{n}=17,14 \%)$. When the article described an original study $(\mathrm{n}=75)$, designs of these studies varied greatly from randomized controlled trials (RCTs) to case series and reports. The majority of the original studies were observational in nature, most commonly cohort studies $(\mathrm{n}=31,41 \%)$. Table 1 displays more details about the characteristics of located studies.

Overall, there were 43 CDS tools located. After reviewing the tools and identified articles, these were classified into three main areas: (1) specific computerbased tools or questionnaires $(\mathrm{n}=8,19 \%)$; (2) clinical prediction rules/classification systems aimed at categorizing patients into various treatment groups $(\mathrm{n}=21,49 \%)$; and (3) theoretical or algorithmic approaches to selecting treatments (treatment algorithms/models) $(\mathrm{n}=14,33 \%)$. Each of these areas and the tools located will be described.

\section{Computer-Based Tools/Questionnaires}

Table 2 provides an inventory of the 8 computer-based devices or questionnaires located for selecting interventions for patients with pain-related MSK disorders. Table 3 provides a summary of the original studies evaluating these tools. Twenty-two manuscripts including three theses [3253] looked at these 8 tools. Three questionnaire-based tools were included: Keele STarT Back Screening Tool (SBST), the Pain Recovery Inventory of Concerns and Expectations (PRICE) questionnaire, and the Orebro Musculoskeletal Pain Questionnaire (OMPQ). We also located 5 tools incorporating computer technology: Repetitive Strain Injury (RSI) QuickScan intervention program, the Pain Management Advisor (PMA), the Decision Support System (DSS) for helping ergonomists better match workers with the work environment, the Soft Tissue Injury Continuum of Care Model with computerized prompts for case managers, and the Work Assessment Triage Tool (WATT). Three of
Fig. 1 Flow chart of article search and relevance selection process

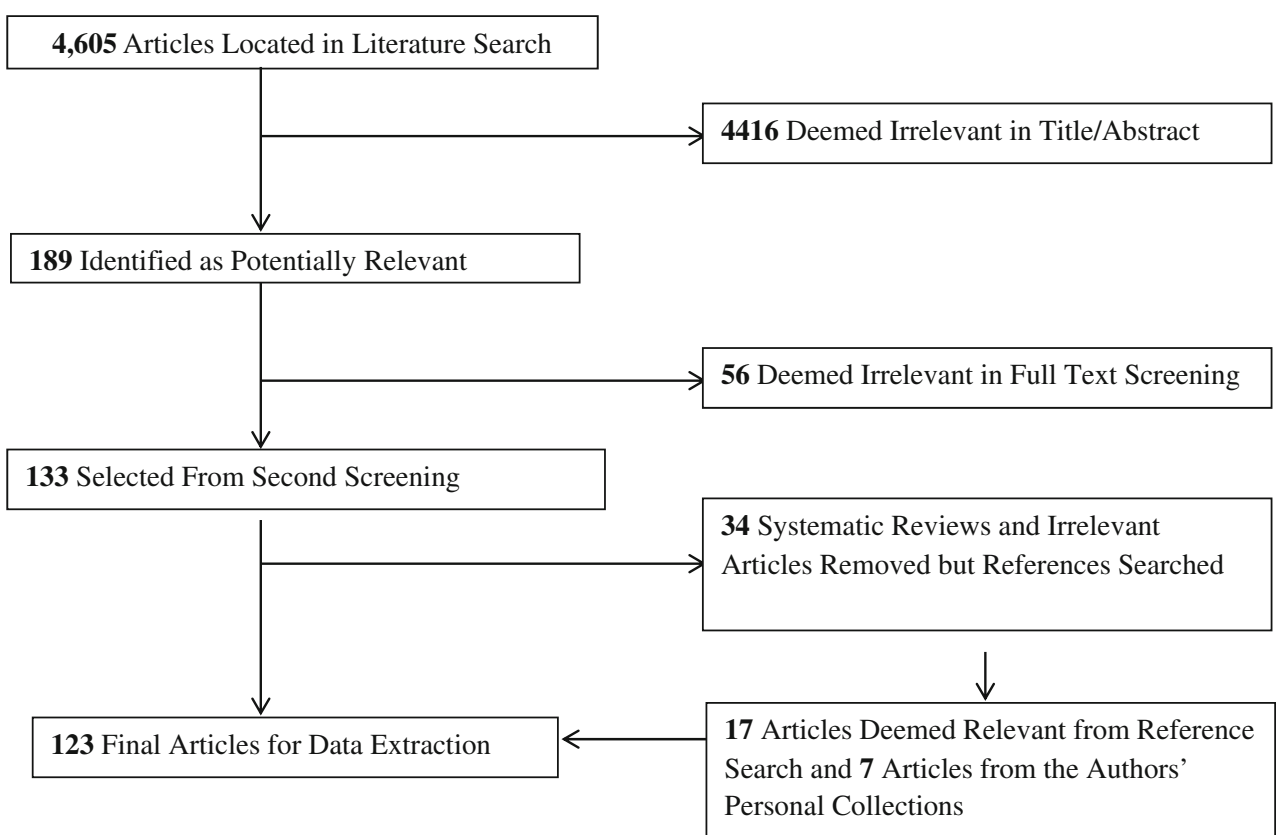


Table 1 Descriptive characteristics of included articles $(n=123)$

\begin{tabular}{|c|c|}
\hline & Number $(\%)$ \\
\hline \multicolumn{2}{|l|}{ Source of evidence } \\
\hline Peer-review journal article & $75(61)$ \\
\hline Commentary/editorial/article summary & $19(15)$ \\
\hline Conference proceeding & $9(7)$ \\
\hline Review & $9(7)$ \\
\hline Study protocol & $6(5)$ \\
\hline Thesis & $5(4)$ \\
\hline \multicolumn{2}{|l|}{ Discipline of lead authors } \\
\hline Health care & $121(98)$ \\
\hline Computing science & $2(2)$ \\
\hline \multicolumn{2}{|l|}{ Geographic location of lead authors } \\
\hline North America & $70(57)$ \\
\hline Europe & $21(17)$ \\
\hline Australasia & $9(7)$ \\
\hline Asia & $4(3)$ \\
\hline Multiple locations & $19(15)$ \\
\hline \multicolumn{2}{|l|}{ Year of publication } \\
\hline 2006-2014 & $101(82)$ \\
\hline $2000-2005$ & $18(15)$ \\
\hline Before 2000 & $4(3)$ \\
\hline \multicolumn{2}{|l|}{ Type of tool discussed in the article } \\
\hline Clinical prediction rule/classification system & $79(64)$ \\
\hline Questionnaire & $15(12)$ \\
\hline Treatment algorithm & $15(12)$ \\
\hline Theoretical/empirical model & $6(5)$ \\
\hline Computer-based tool & $8(7)$ \\
\hline \multicolumn{2}{|l|}{ Condition aimed at by tool } \\
\hline Low back pain & $69(56)$ \\
\hline Neck/shoulder/arm pain & $21(17)$ \\
\hline General MSK disorders & $17(14)$ \\
\hline Knee/ankle pain & $6(5)$ \\
\hline Upper extremity pain & $3(2)$ \\
\hline Serious pathology (fractures, etc.) & $5(4)$ \\
\hline Thoracolumbar injury & $2(2)$ \\
\hline \multicolumn{2}{|l|}{ Reasoning method } \\
\hline Rule-based & $109(89)$ \\
\hline Other (e.g., neural network, decision tree) & $8(7)$ \\
\hline Unclear & $6(5)$ \\
\hline \multicolumn{2}{|l|}{ Study design of peer-review studies located $(\mathrm{n}=75)$} \\
\hline \multicolumn{2}{|l|}{ Experimental } \\
\hline Randomized controlled trial & $12(16)$ \\
\hline Quasi-experimental & $4(5)$ \\
\hline \multicolumn{2}{|l|}{ Observational } \\
\hline Cohort study & $31(41)$ \\
\hline Case control/case report/case series & $15(20)$ \\
\hline Cross-sectional study & $6(8)$ \\
\hline Secondary analysis & $5(7)$ \\
\hline Methodological study & $2(3)$ \\
\hline
\end{tabular}

these tools were aimed at workers with low back pain (SBST, PRICE and OMPQ), 2 were aimed at work-related upper extremity disorders (RSI QuickScan and DSS), 2 were aimed at general work-related MSK injuries (WATT and Soft Tissue Continuum of Care), and 1 aimed at assisting physicians in managing patients with chronic pain (PMA).

Most of these tools had some psychometric testing in the way of validation of items, concurrent validity, acceptability of the tool, accuracy of the classification as well as testing the effectiveness of the tool compared to standard treatment. Nevertheless, this testing has been preliminary, and a more exhaustive validation process involving randomized controlled trials at multiple sites and settings is needed for all of the tools. Four of the tools [34, 35, 37, 38] showed positive preliminary results regarding the use of the tool to determine appropriate treatments for managing some MSK conditions. However, one tool (RSI QuickScan) did not prove to be effective for reducing work disability or cost-effective [40,52], and two studies did not have clear positive or negative results regarding the tools evaluated (SBST and WATT) [33, 42]. One student thesis evaluated the utility of the OMPQ as a clinical decision support tool for workers' compensation claimants, with negative results [39]. However, the OMPQ was initially developed as a screening or prognostic tool, not explicitly as a CDS tool. In addition, one protocol of a cluster RCT that attempts to use the OMPQ as a CDS tool for selecting interventions for patients with LBP was found [44]. The results of this RCT are still unpublished, so it is unknown how well the OMPQ functions as a CDS tool. Three other studies [32, 36, 41] only looked at the development phase of the tools (WATT and PRICE). Thus, evidence is limited regarding validity evidence of these CDS tools. For details of the measurement properties of the CDS tools found, see Table 4.

\section{Treatment Algorithms/Decision-Models}

Of the 22 articles [54-75] discussing treatment algorithms/models, there were 15 original studies evaluating 14 different algorithms or decision-models (theoretical or empirical) for selecting interventions for patients with MSK disorders. Details of these algorithms/models and the studies can be found in Table 5. Nine of the studies [54-61, 76] looked at low back pain, 2 discussed knee disorders [62, 63], 2 discussed shoulder disorders [64, 65] and 2 examined other body regions (wrist and neck) [66, 67]. Research designs used in these studies varied greatly, with the observational cohort study being the most common among them. Methodologies and types of algorithms were also wide-ranging, making the analysis of these studies 


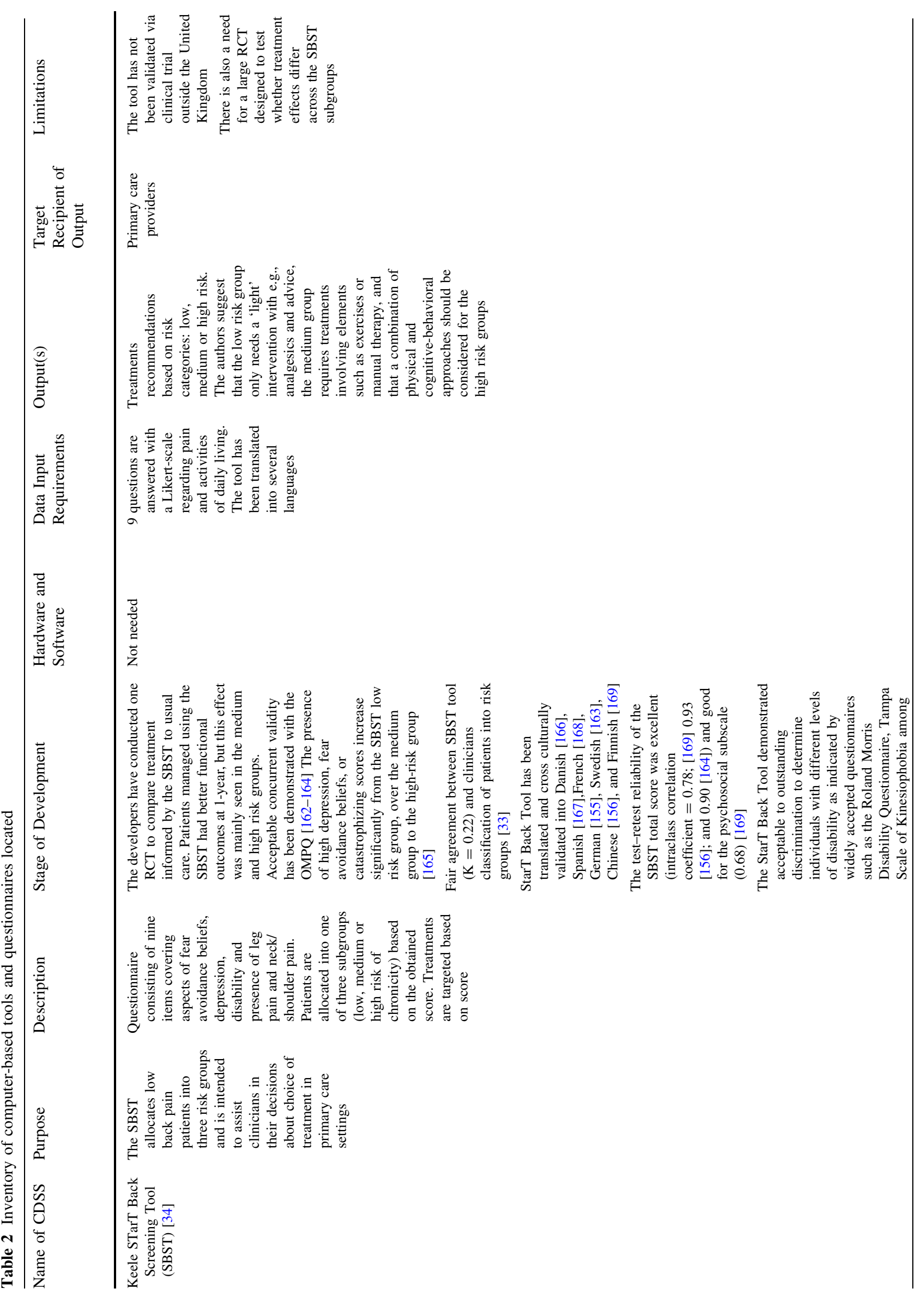




\begin{tabular}{|c|c|c|c|}
\hline & 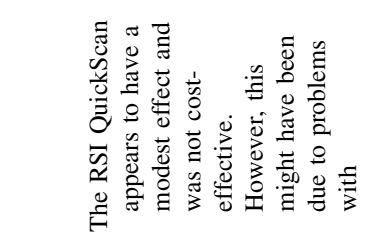 & 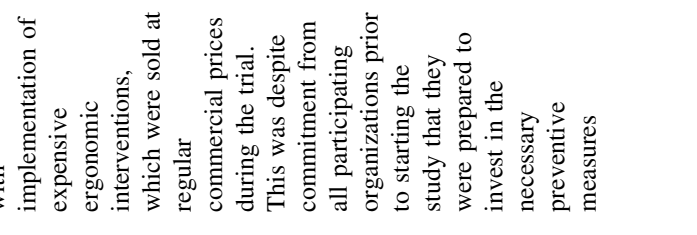 & 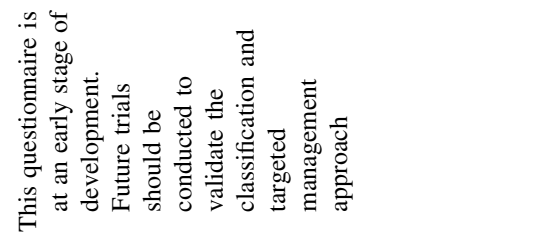 \\
\hline 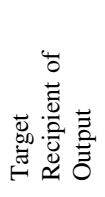 & 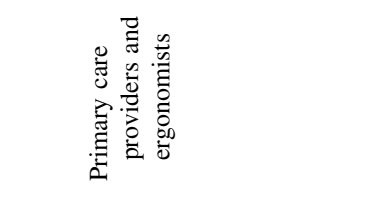 & & 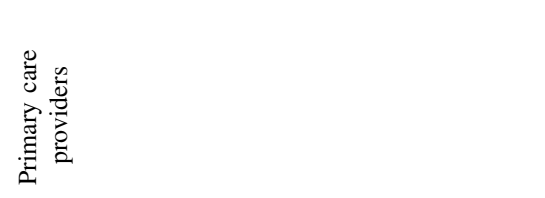 \\
\hline & 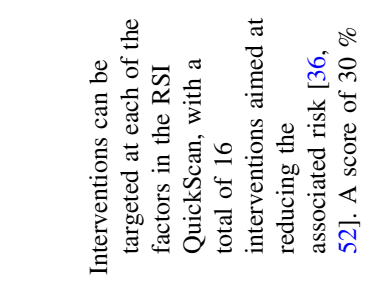 & 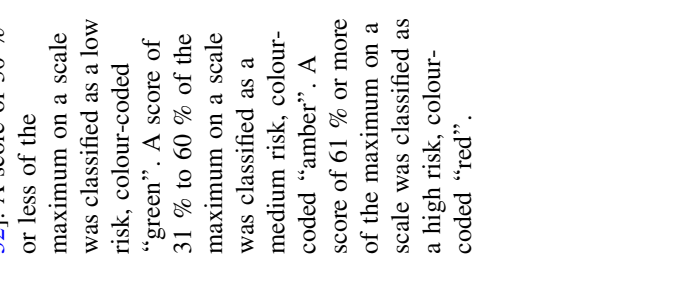 & 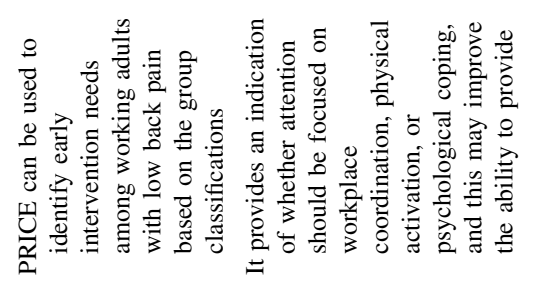 \\
\hline 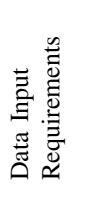 & 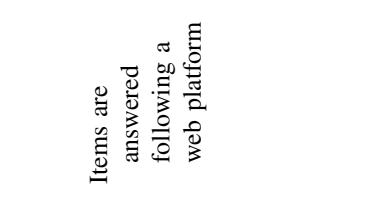 & & 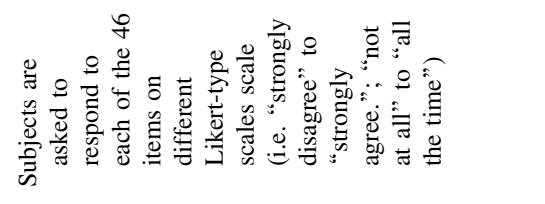 \\
\hline 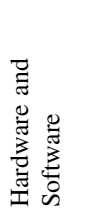 & 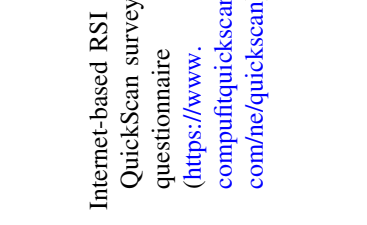 & & 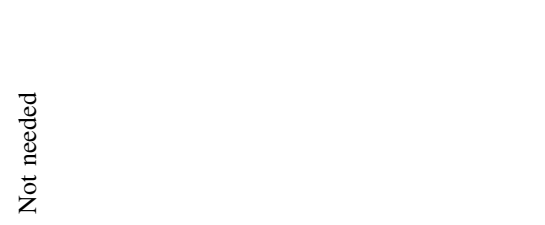 \\
\hline & 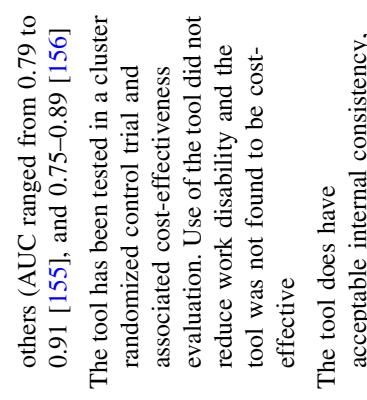 & 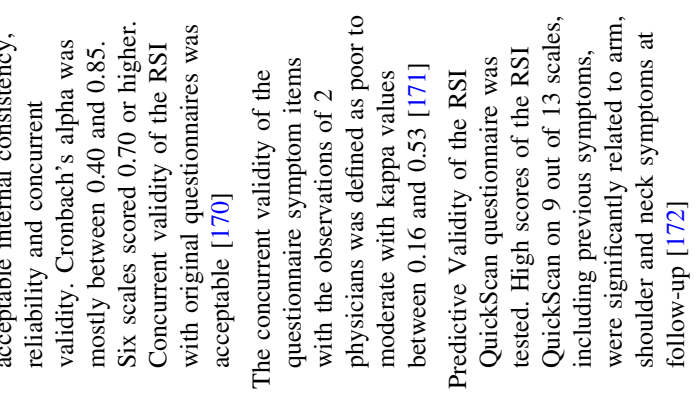 & 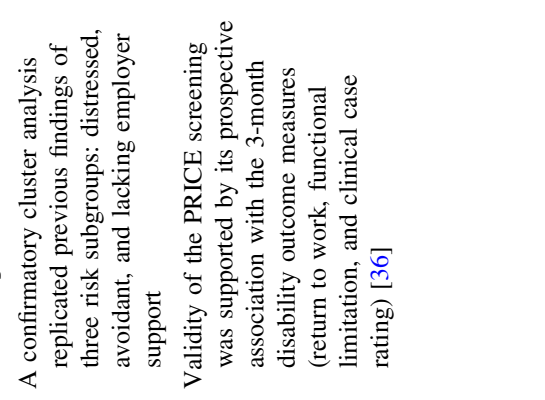 \\
\hline & 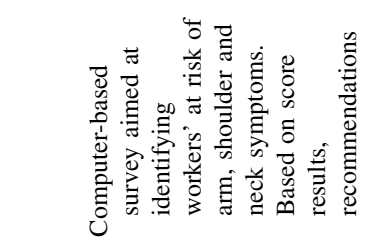 & 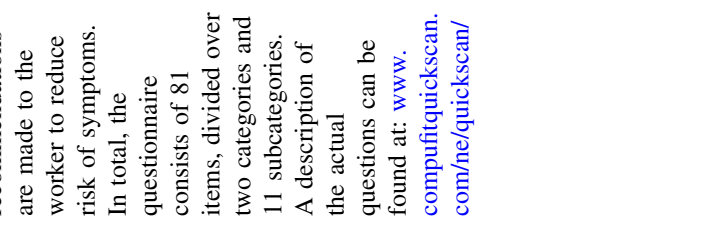 & 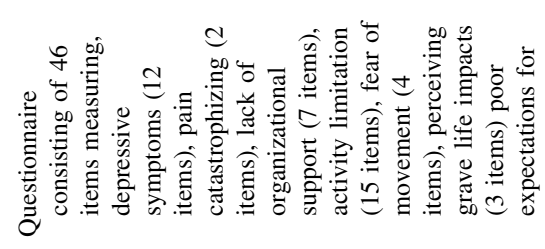 \\
\hline & 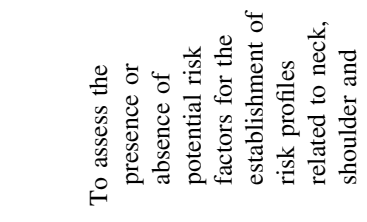 & 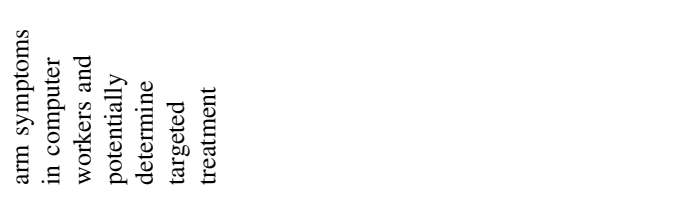 & 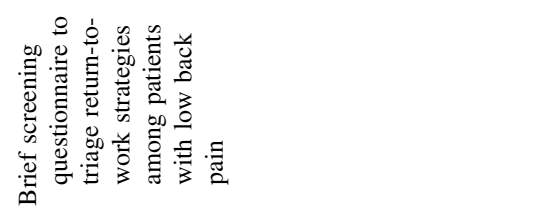 \\
\hline & 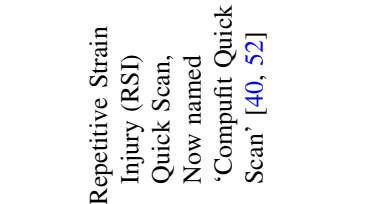 & & 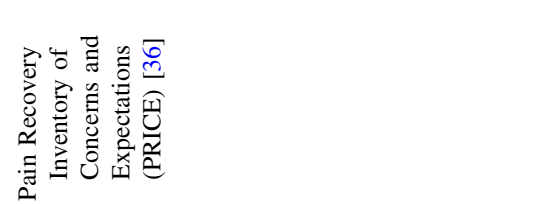 \\
\hline
\end{tabular}




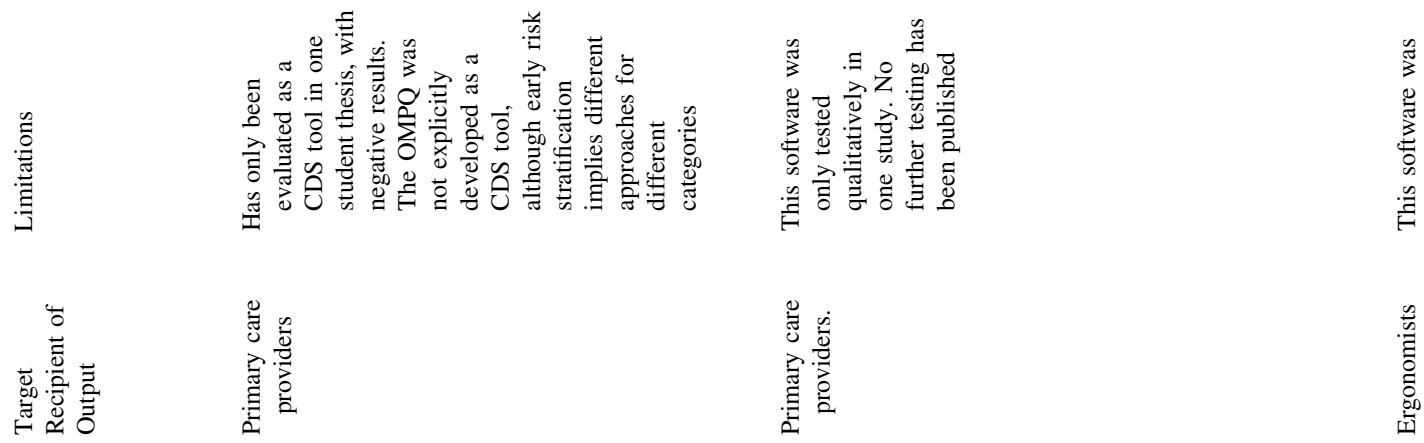
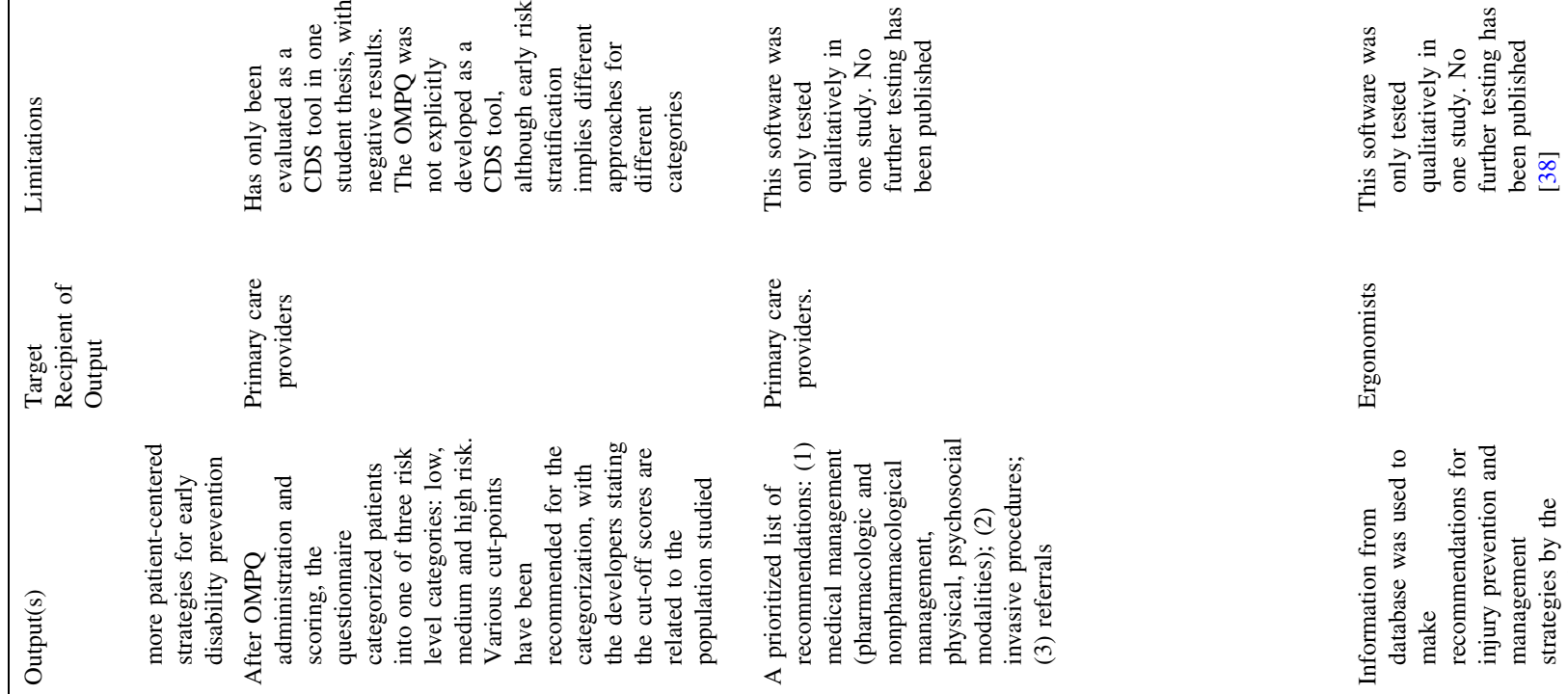

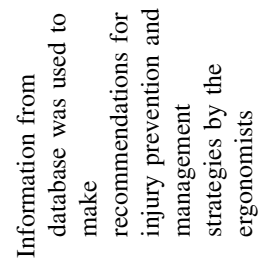

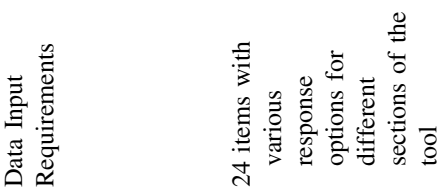

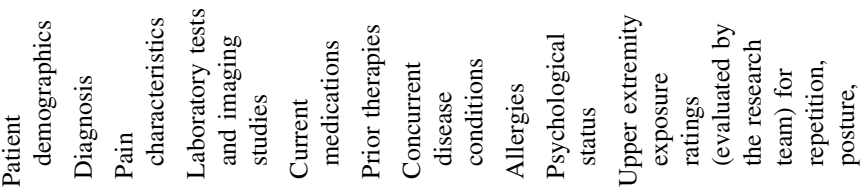

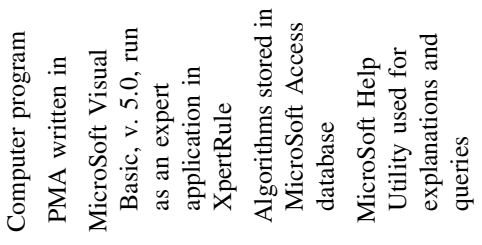

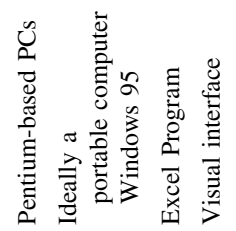

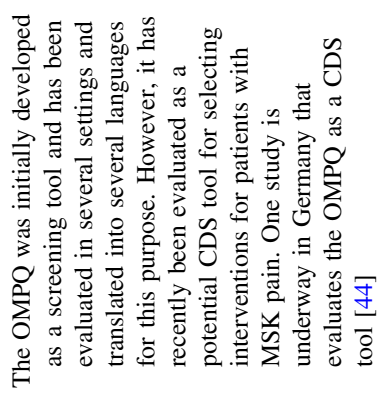

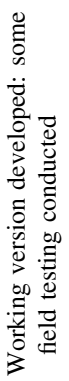

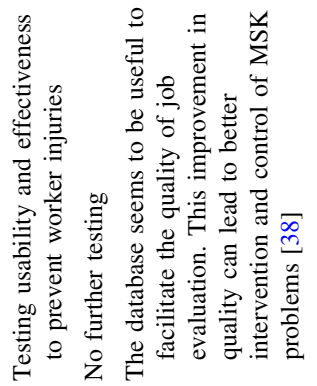

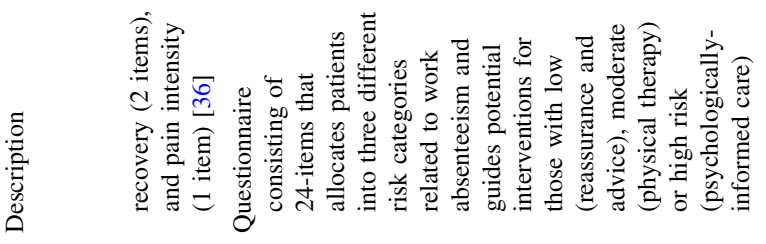

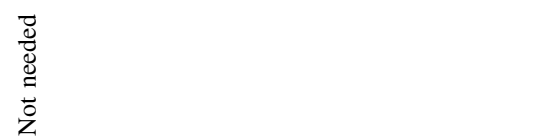

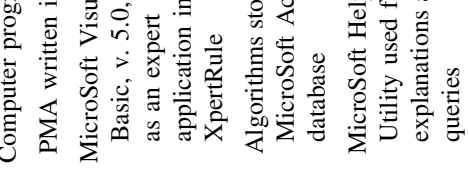
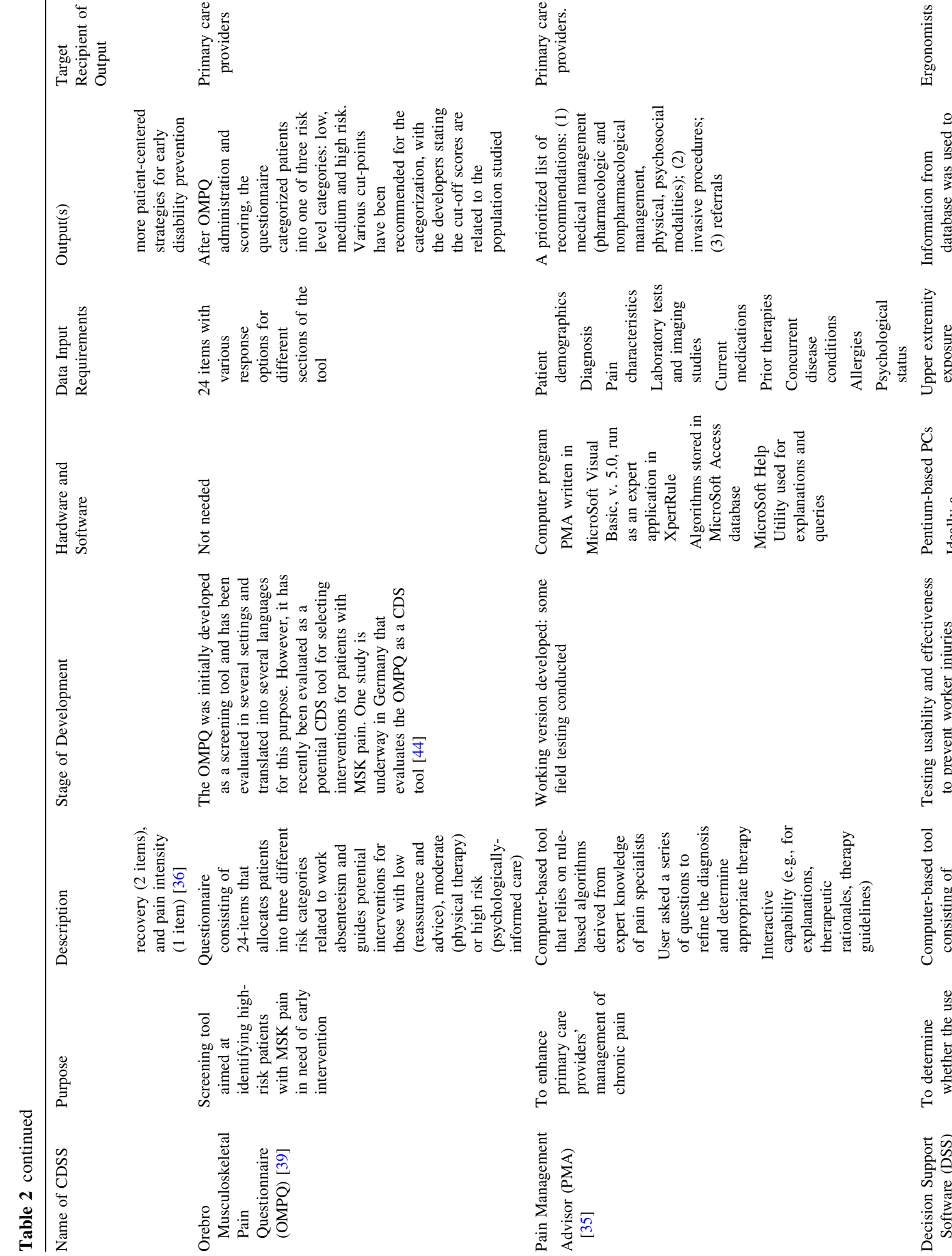

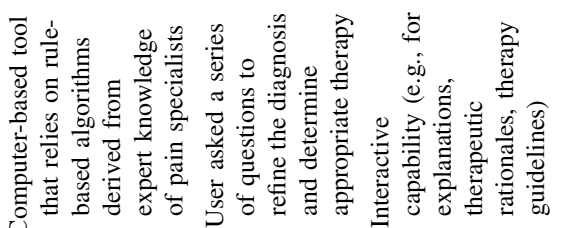
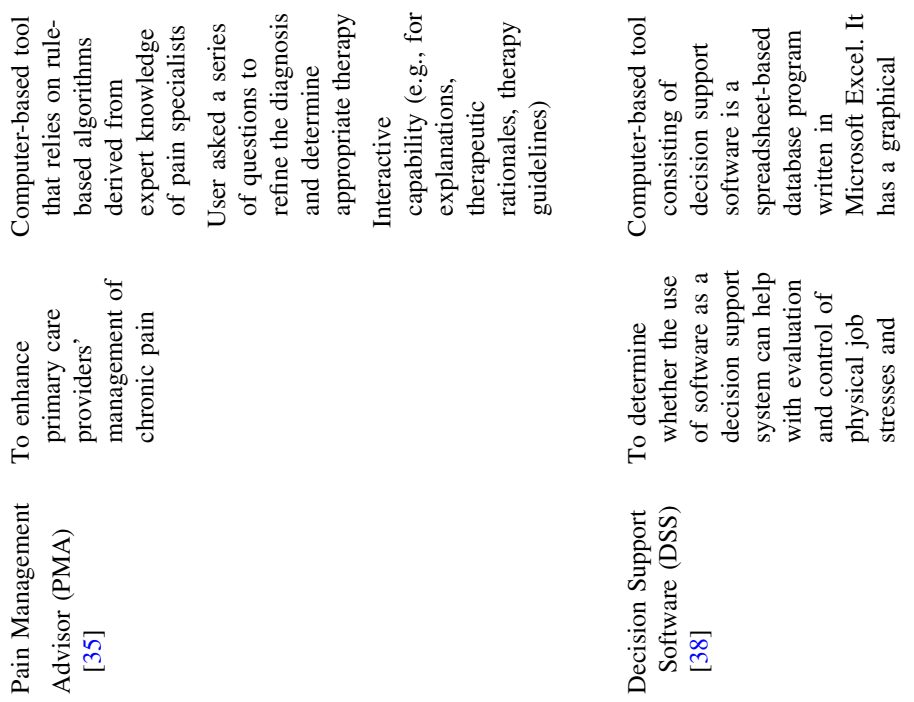


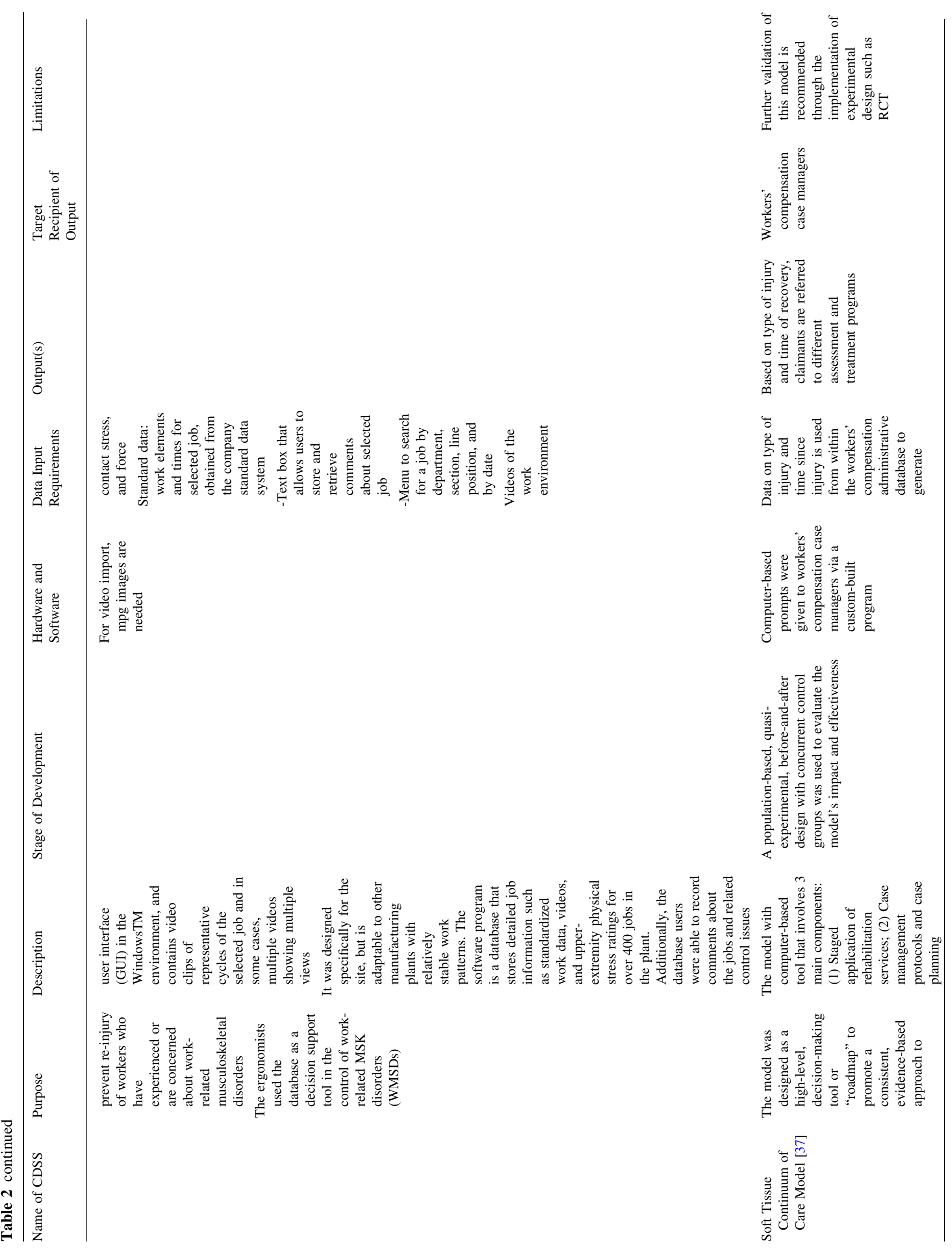




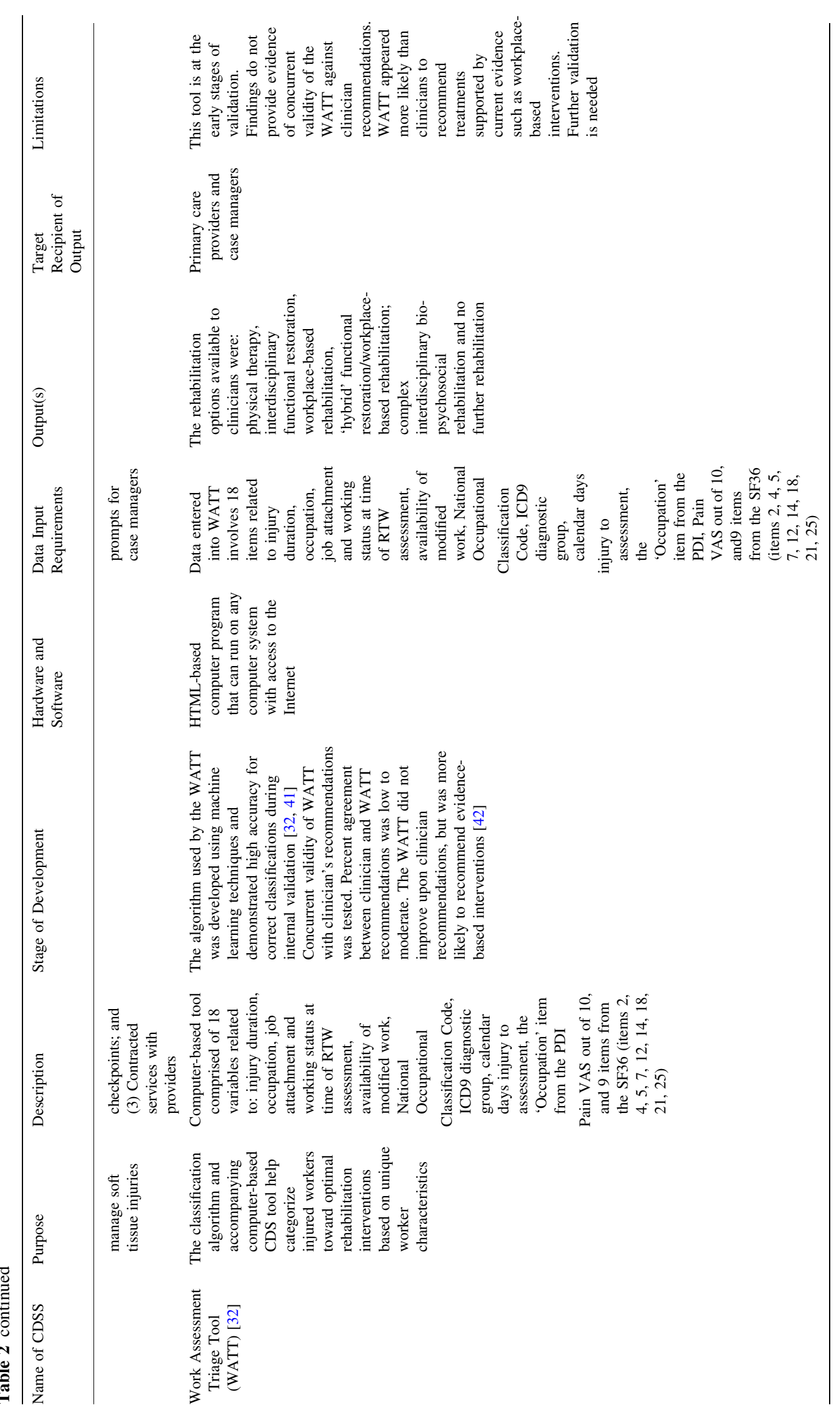




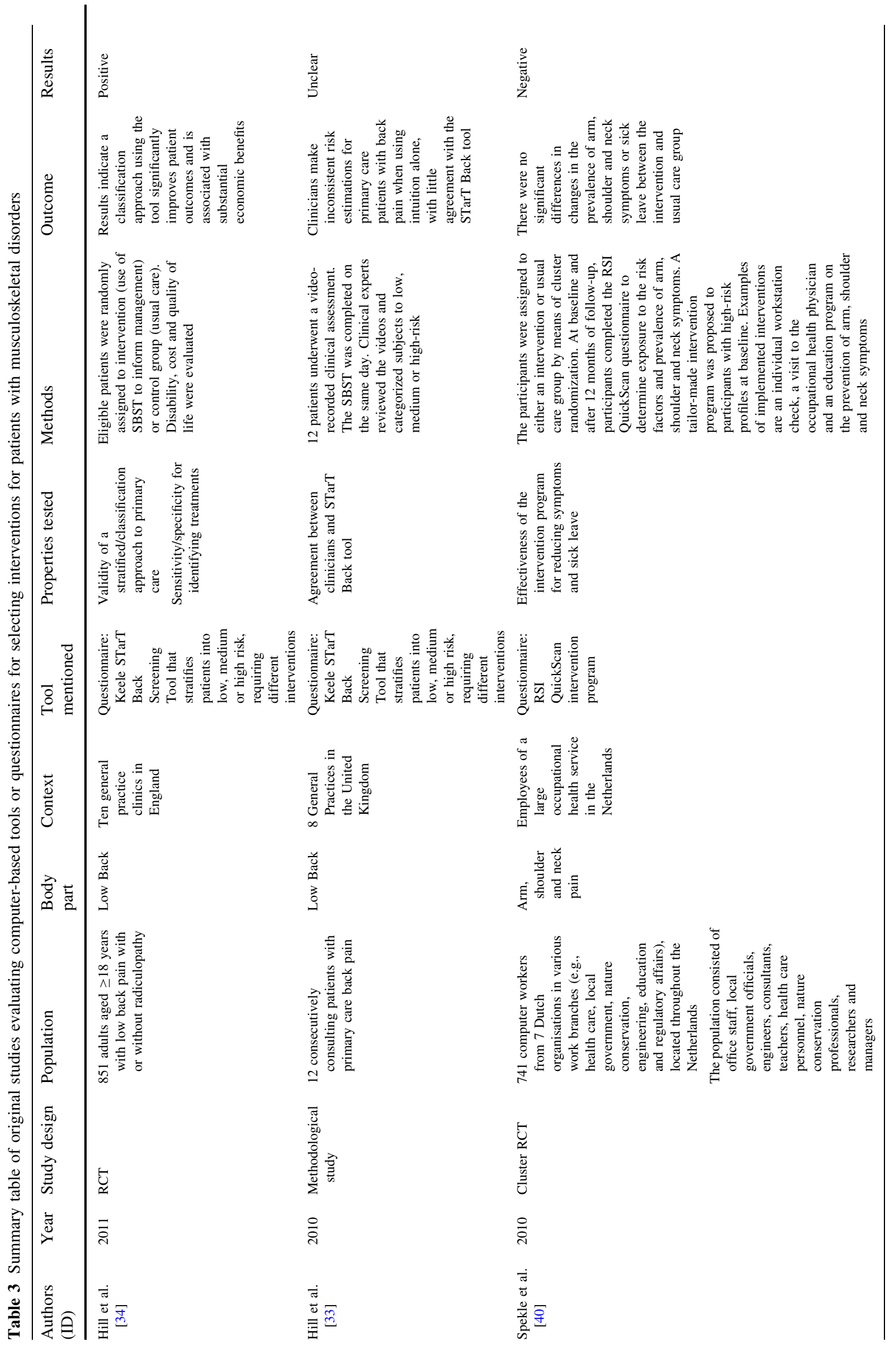




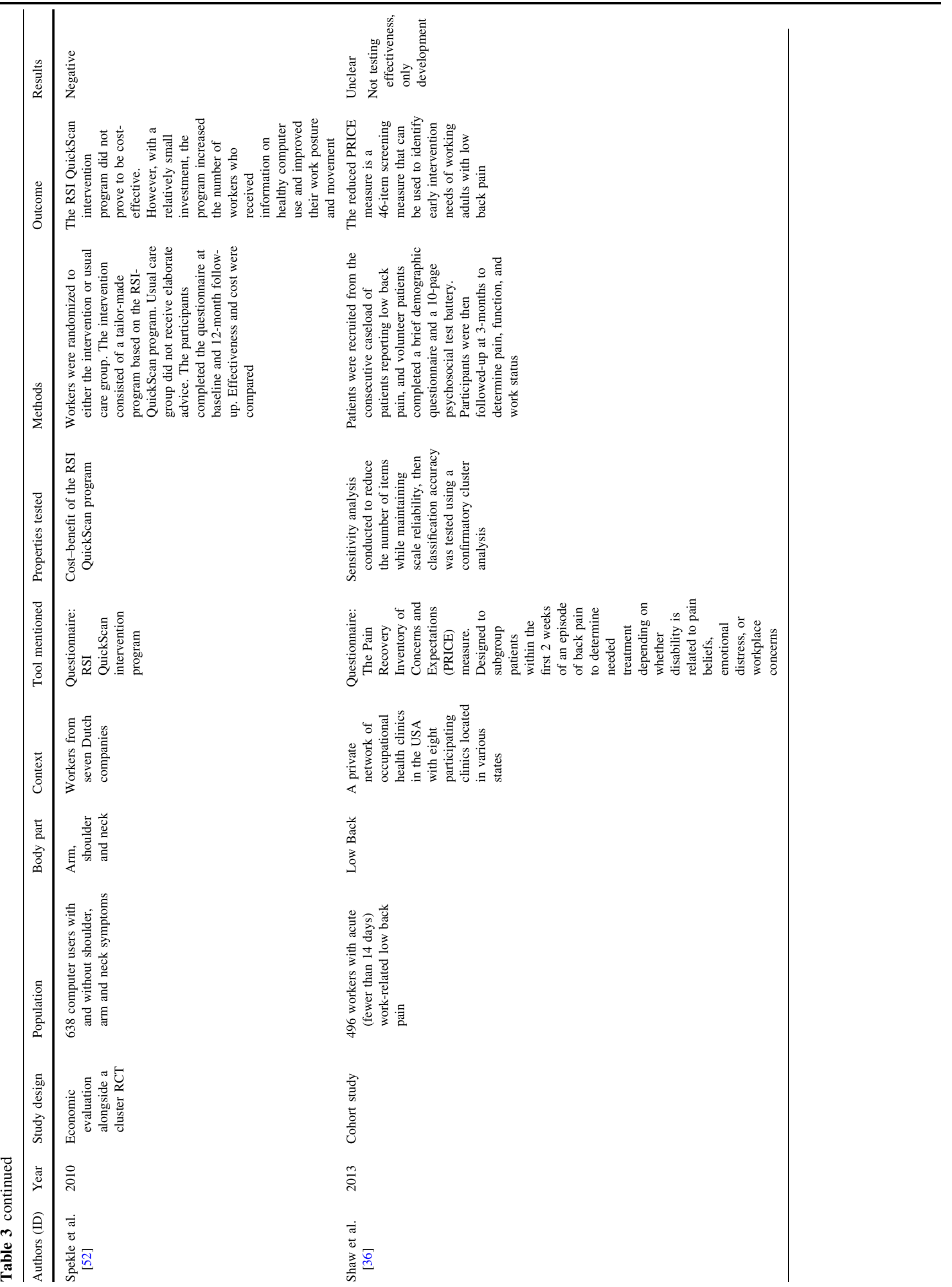




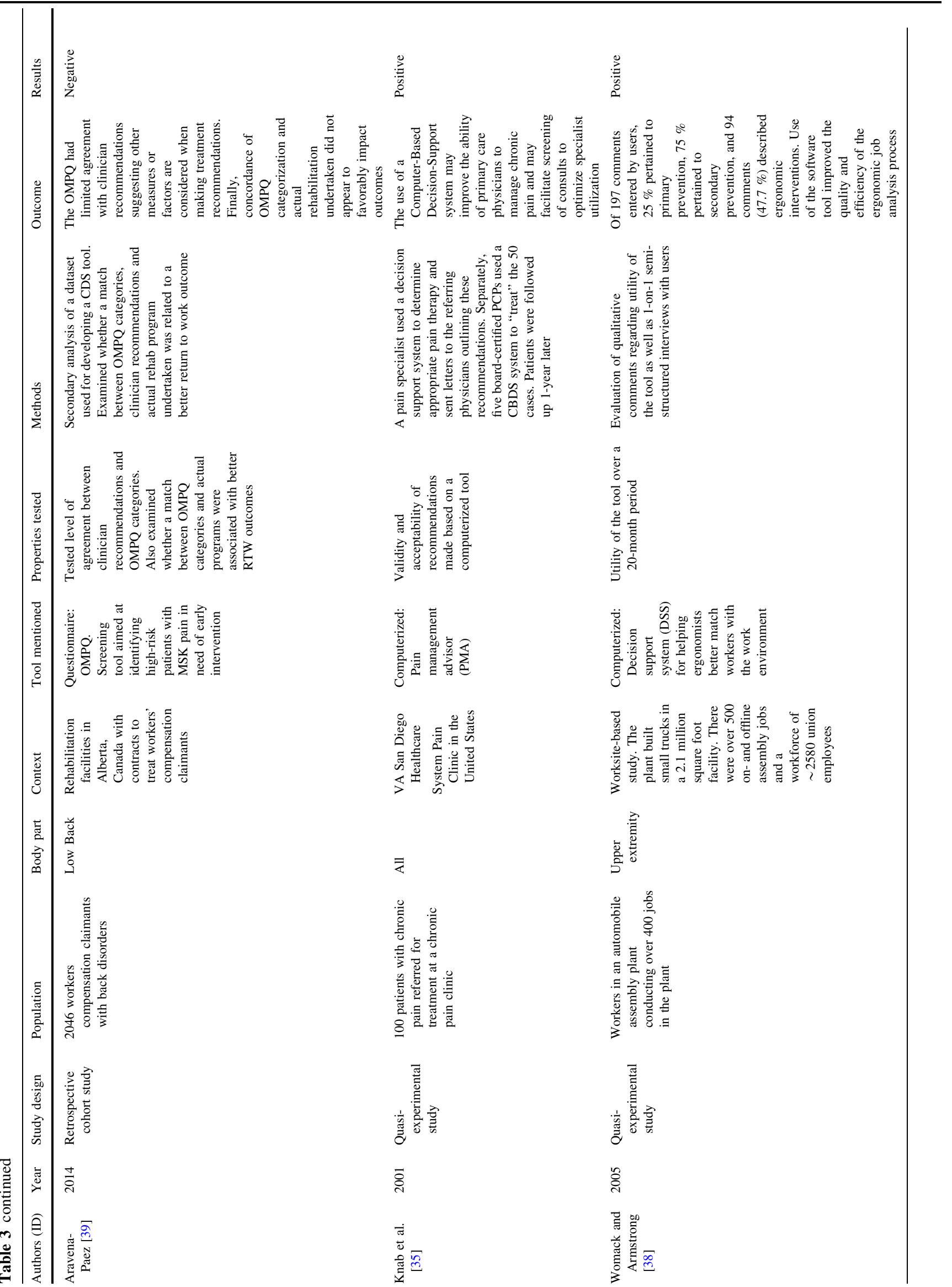




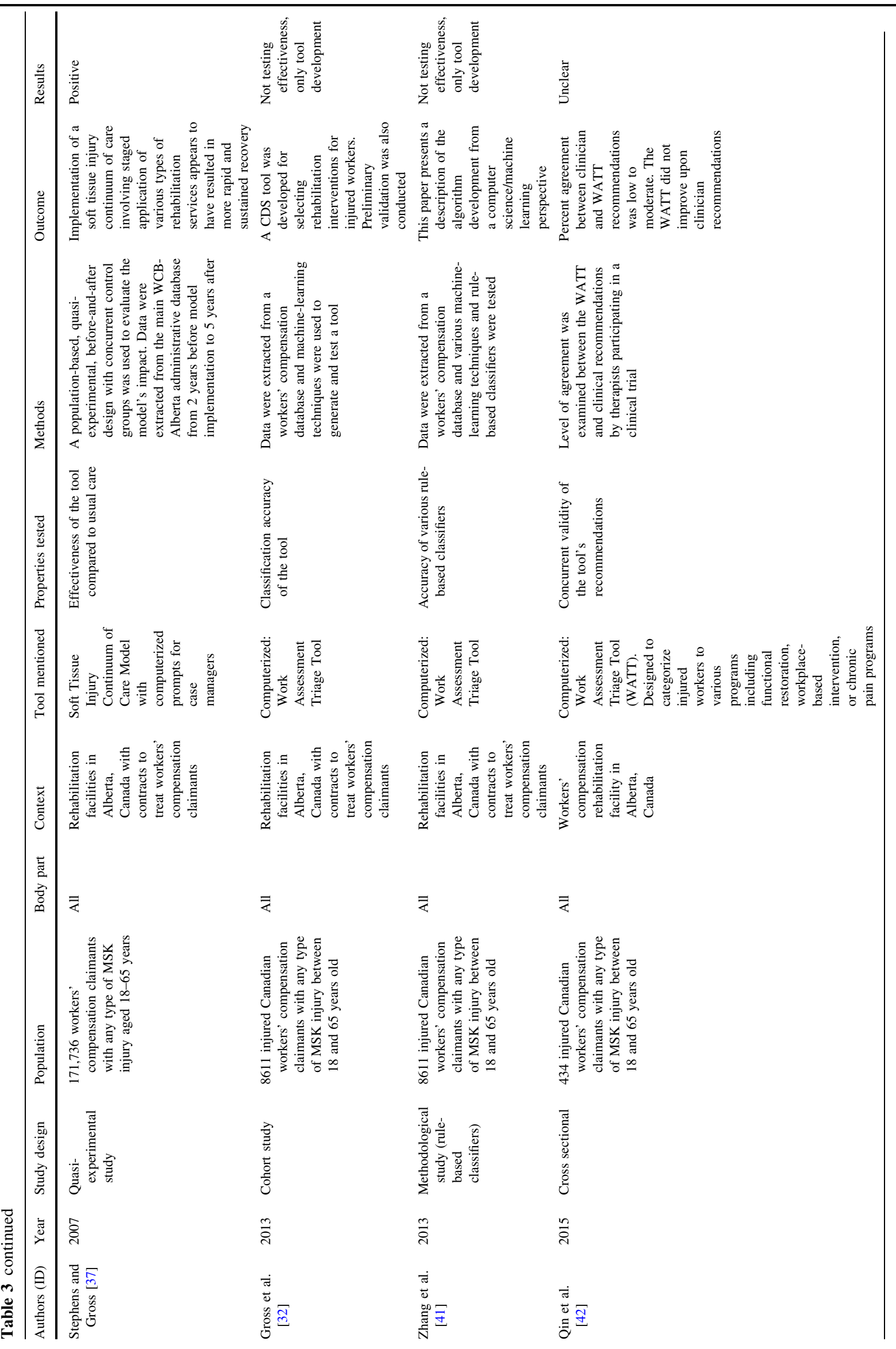


Table 4 Summary of the quality of measurement properties of the computer-based tools or questionnaires located

\begin{tabular}{lllllll}
\hline Tool & $\begin{array}{l}\text { Internal } \\
\text { consistency }\end{array}$ & $\begin{array}{l}\text { Face } \\
\text { validity }\end{array}$ & $\begin{array}{l}\text { Content } \\
\text { validity }\end{array}$ & $\begin{array}{l}\text { Criterion } \\
\text { validity* }\end{array}$ & $\begin{array}{l}\text { Construct } \\
\text { validity }\end{array}$ & $\begin{array}{l}\text { Reproducibility } \\
\text { (agreement/reliability) }\end{array}$ \\
\hline StarT Back & + & + & + & $+*$ & + & + \\
RSI Quick Scan & + & + & + & + & + & + \\
PRICE & + & + & + & + & + & - \\
PMA & - & + & + & + & - & - \\
DSS & - & + & + & + & + & - \\
Soft Tissue Model & - & + & + & + & + \\
WATT & - & + & + & & - \\
\hline
\end{tabular}

+ Quality of measurements properties were based on guidelines established by Terwee et al. [31]

(+) Criterion accomplished

(-) Criterion not accomplished

* Comparison was performed with reference standards

challenging. Most of the algorithms or decision models were developed to determine possible treatment paths. Nevertheless, most testing of these algorithms/decision models was preliminary or exploratory (e.g., small sample size, secondary analyses of previous collected data, lack of replication or validation samples, use of research designs that are prone to bias including case series, cross sectional or cohort studies rather than randomized controlled trials). Nine of these algorithms [54, 58, 62-67, 76] seemed to lead to positive results when deciding on intervention strategies. Nevertheless, one study [56] found that the use of the algorithm would not result in better outcomes for patients with low back pain. Four studies [55, 57, 59, 61] only looked at the development of an algorithm/model without associated testing of it.

\section{Clinical Prediction Rules/Classification Systems}

The remaining 79 articles [76-154] looked at 21 unique clinical prediction rules or classification systems. Four articles described the clinical prediction rules in general. Most of these studies targeted rules for identifying responders to interventions for low back pain (8 rules) followed by neck pain (6 rules), patellofemoral pain (3 rules), lateral epicondylagia (2 rules), ankle sprain (1 rule) and thoracolumbar injury (1 rule). For details on the clinical prediction rules and classification systems found in this scoping review, see Table 6 . The rules were developed to determine response to specific treatments that included spinal manipulation, stabilization exercises, McKenzie approach, mechanical traction, Pilates-based exercise, foot orthoses, patellar taping, or general classification models.
From the rules looking at back pain (8 rules in total involving 47 articles [77-121, 150, 152]), three rules (rules for manipulation and stabilization exercise, and the treatment-based classification system) have been the most commonly studied. Confirmatory evaluation of these rules has shown mixed or unsuccessful results. The remaining 5 rules (rules for the McKenzie approach, mechanical traction, Pilates, and the CBI Health classification system) have been developed empirically or theoretically but no confirmatory testing has been conducted. Thus, it is unknown if the results from these studies would provide clarification regarding management of patients with back pain.

Six rules discussed in 18 articles targeted neck pain [122-139]. From these rules, only one (treatment-based classification system) showed positive results when tested in case series, pilot and cohort studies. However, this rule has not been tested in a randomized controlled trial. The remaining 5 rules for neck pain were either unsuccessful (rule for thoracic manipulation) or had no confirmatory testing evidence. From the rules developed for patellofemoral pain, 2 rules discussed in 5 articles [140-143, 146] (1 rule for patellar taping and 1 for foot orthoses) were not tested further and 1 rule for lumbopelvic manipulation obtained unsuccessful results when tested in a separate sample. The remaining rules developed for lateral epicondylalgia (2 rules in 2 articles [147, 149]), ankle sprain ( 1 rule in 1 article [148]) and thoracolumbar injury (1 rule in 2 articles [144, 145]) did not have additional testing. Of note, there were 3 interventions where two separate rules were generated for the same condition (traction for low back pain, manipulation for neck pain, and foot orthoses 


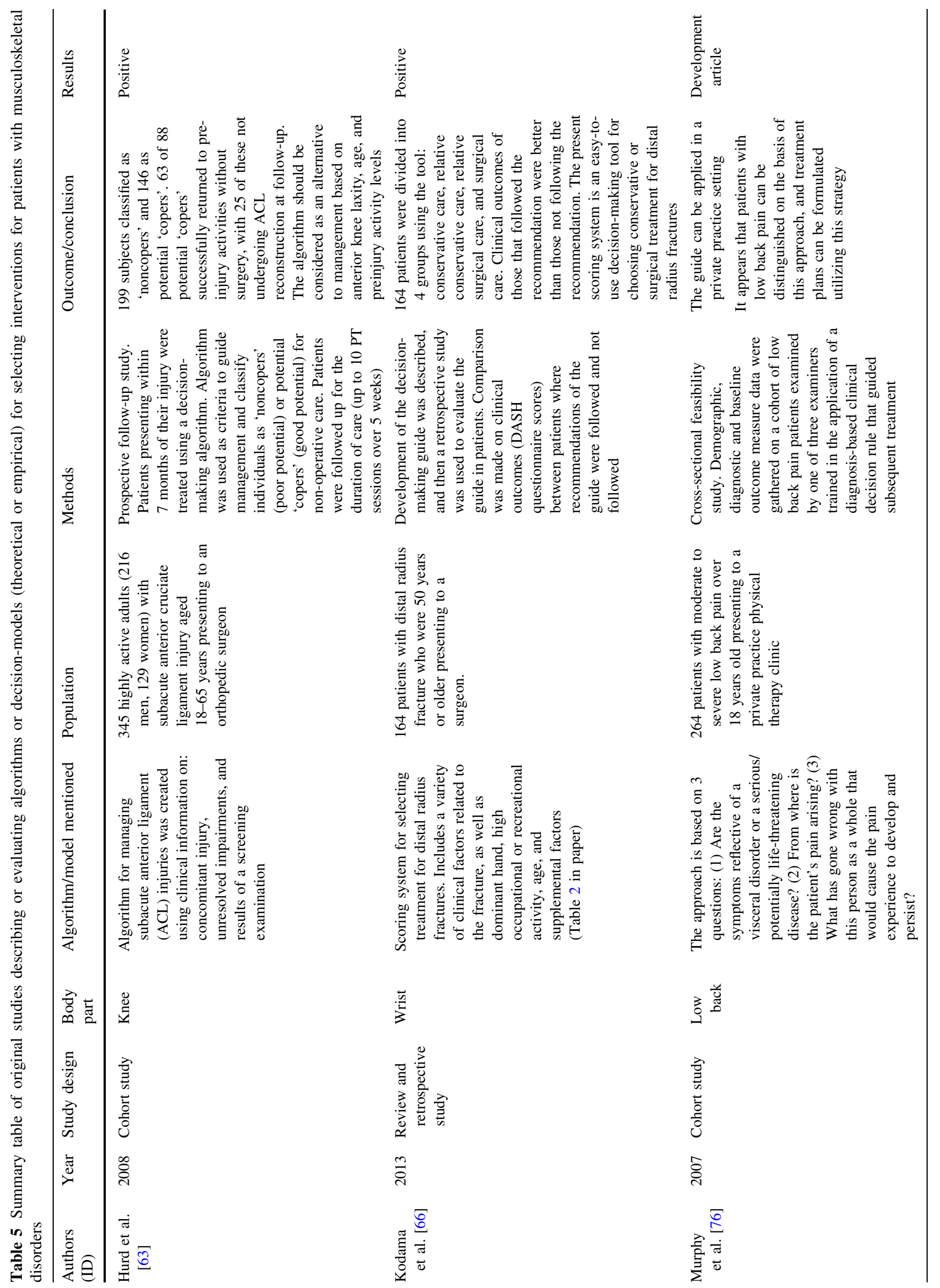




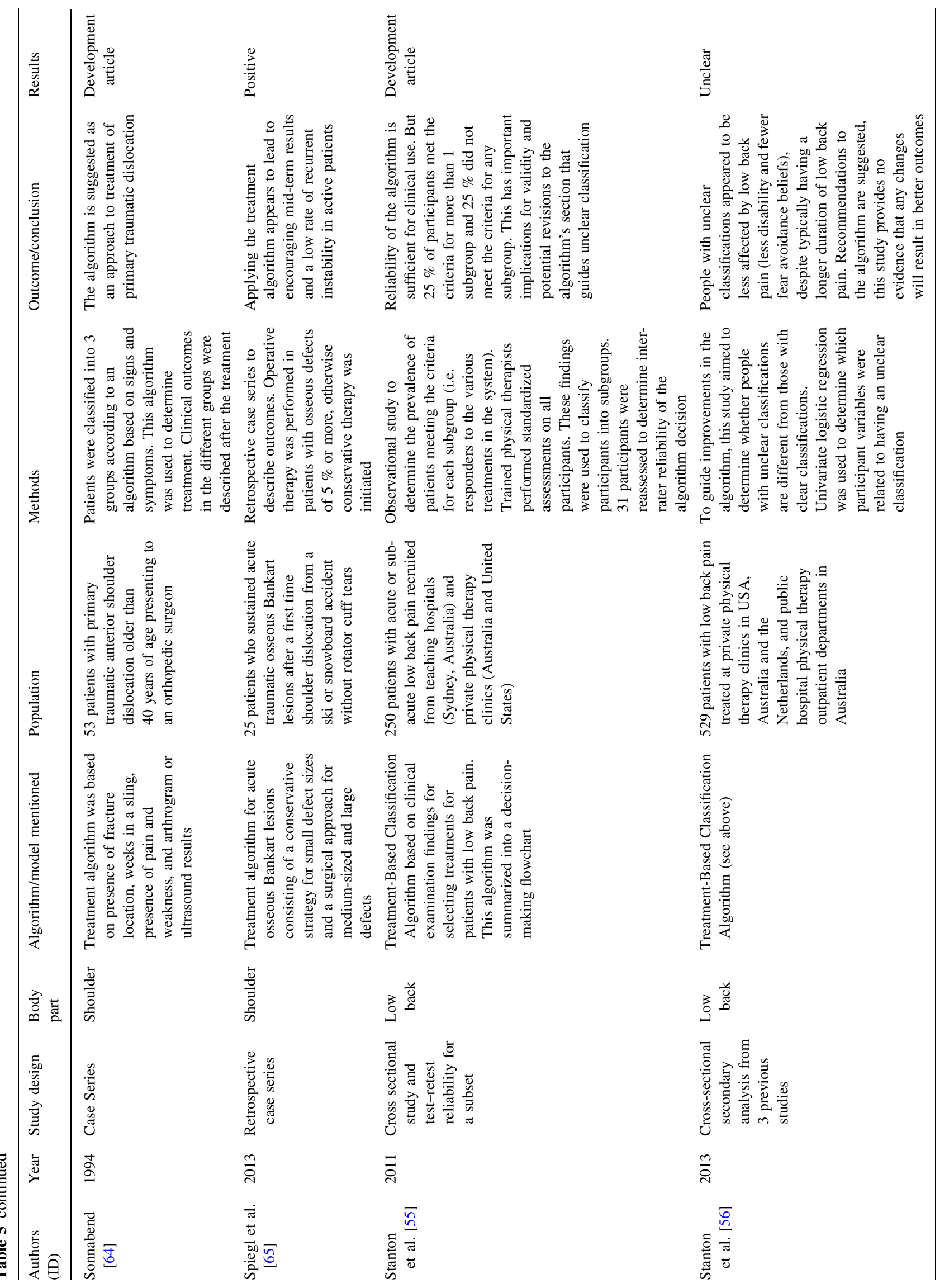




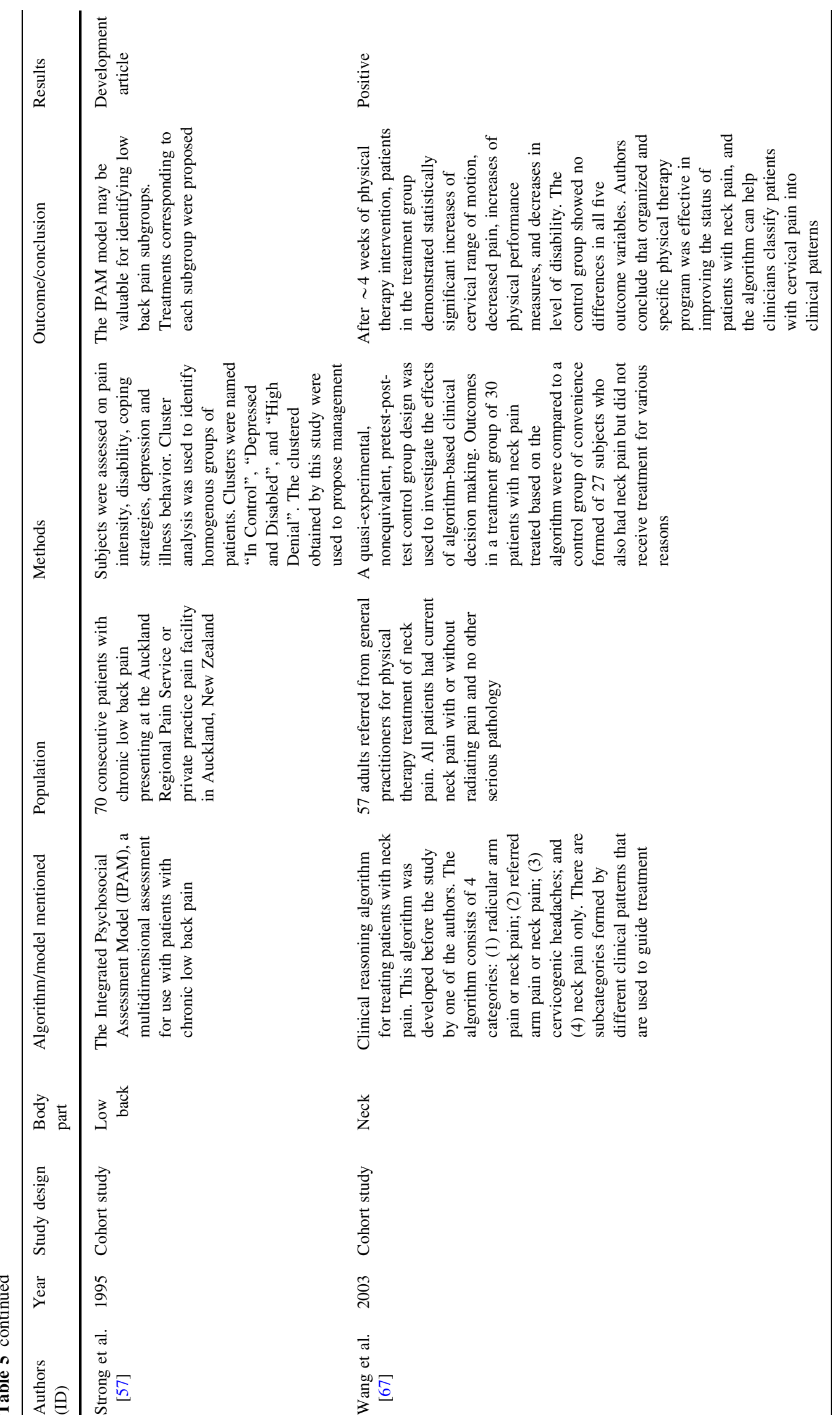




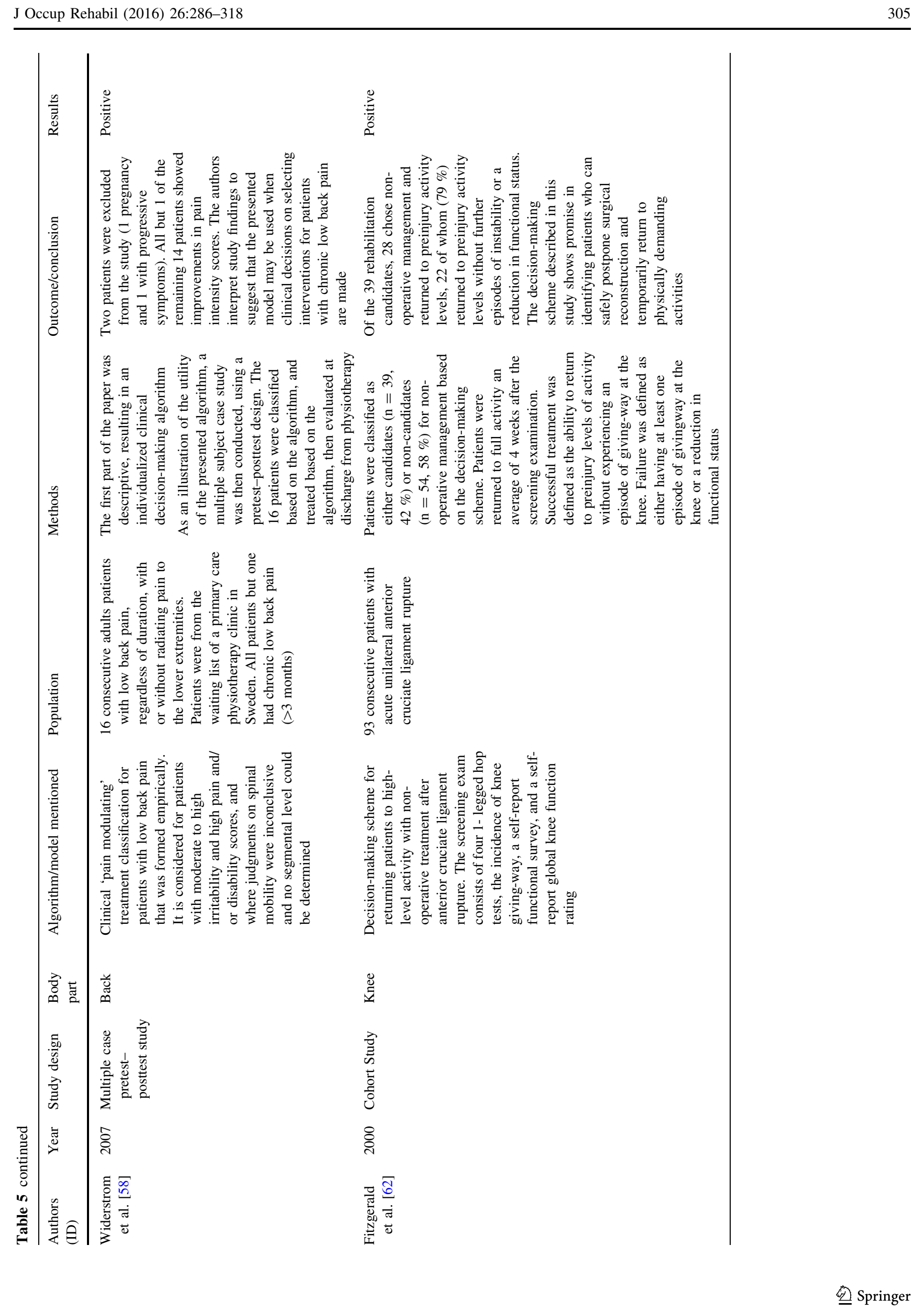




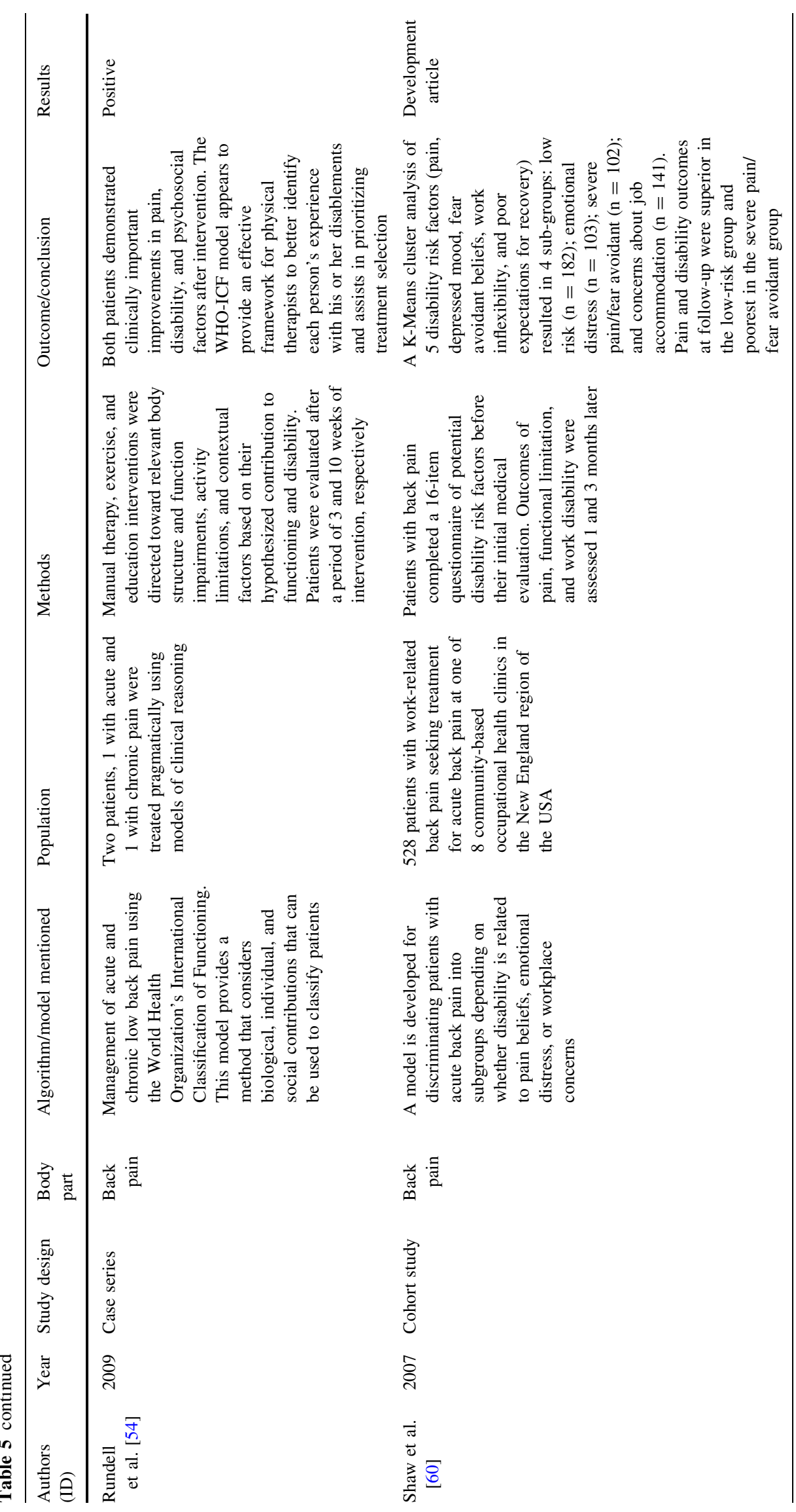




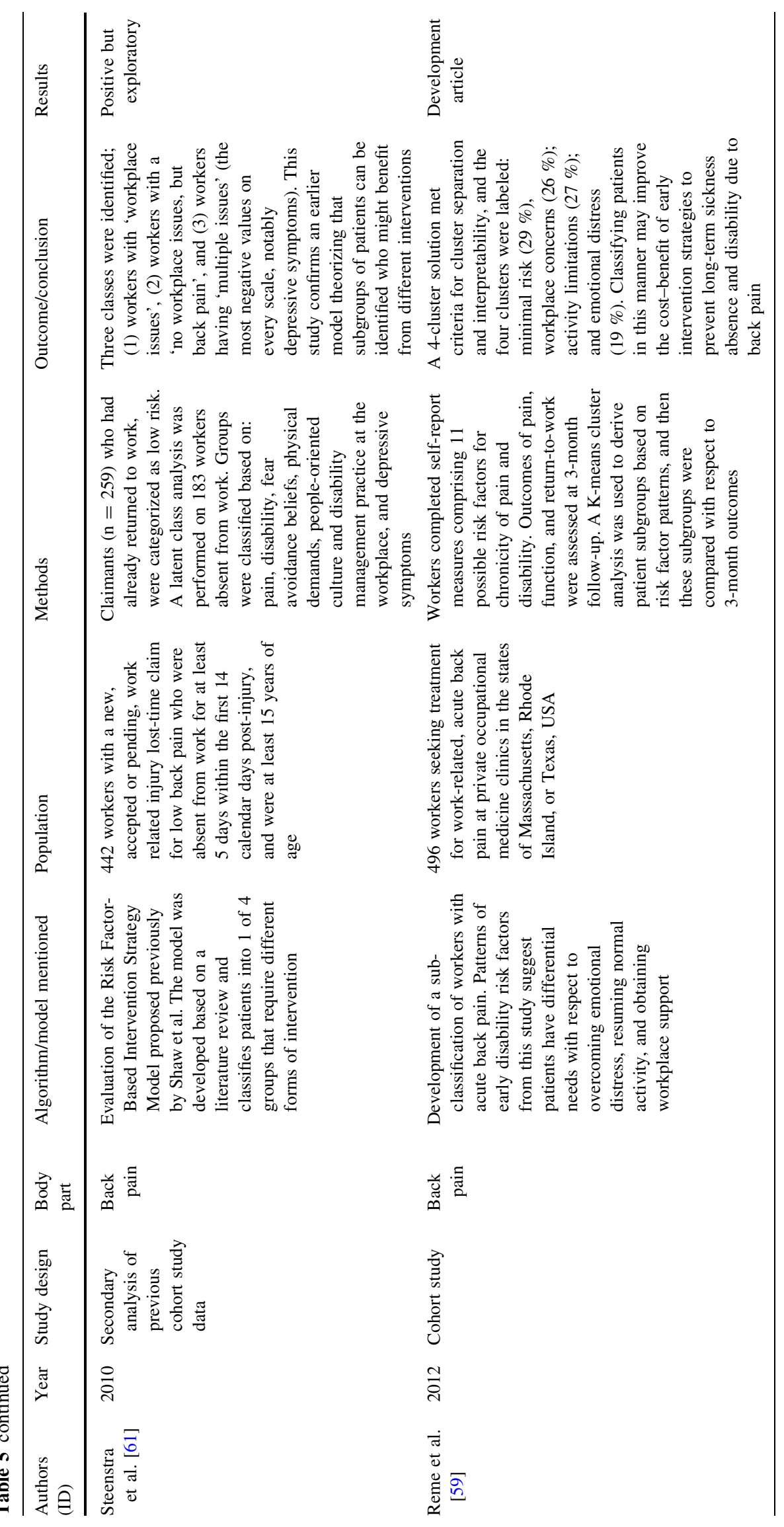


Table 6 Summary of clinical prediction rules and classification systems for painful musculoskeletal conditions

\begin{tabular}{|c|c|c|}
\hline Condition & Purpose of rule/system & Evaluation status of the rule/system \\
\hline Low back pain & $\begin{array}{l}\text { Identifying responders to spinal manipulation } \\
{[77-97,119,120]}\end{array}$ & $\begin{array}{l}\text { Rule developed empirically } \\
\text { Confirmatory testing in additional samples, including workers, has shown } \\
\text { mixed results } \\
\text { Unsuccessful evaluation via clinical trial } \\
\text { Patients positive for the main factors in the rule (symptom duration }<16 \text { days } \\
\text { and no symptoms distal to the knee) respond to other interventions such as } \\
\text { McKenzie therapy }\end{array}$ \\
\hline Low back pain & $\begin{array}{l}\text { Treatment-based classification system } \\
{[55,56,97-111]}\end{array}$ & $\begin{array}{l}\text { Rule developed theoretically } \\
\text { Empirical testing has had mixed results } \\
\text { Mixed evaluations via clinical trial } \\
\text { Reliability of mobilization and stabilization subgroups has been } \\
\text { unacceptable in some studies } \\
\text { Questionable utility of the system as } 25 \% \text { of patients fall into multiple } \\
\text { subgroups and } 25 \% \text { remain unclassified }\end{array}$ \\
\hline Low back pain & $\begin{array}{l}\text { Identifying responders to stabilization } \\
\text { exercise }[92,97,110,112]\end{array}$ & $\begin{array}{l}\text { Rule developed empirically } \\
\text { Confirmatory testing in additional samples has had mixed results } \\
\text { Stabilization and manipulation rules do not represent mutually exclusive } \\
\text { subgroups }\end{array}$ \\
\hline Low back pain & $\begin{array}{l}\text { Identifying responders to McKenzie } \\
\text { approach }[95,97,113]\end{array}$ & $\begin{array}{l}\text { Rule developed empirically } \\
\text { No confirmatory testing } \\
\text { Prevalence testing of McKenzie classifications shows overlap with other } \\
\text { prediction rules }\end{array}$ \\
\hline Low back pain & $\begin{array}{l}\text { Identifying non-responders to spinal } \\
\text { manipulation [114] }\end{array}$ & $\begin{array}{l}\text { Rule developed empirically } \\
\text { No confirmatory testing }\end{array}$ \\
\hline Low back pain & $\begin{array}{l}\text { Identifying responders to mechanical traction } \\
{[115,116]}\end{array}$ & $\begin{array}{l}\text { Two separate rules developed empirically } \\
\text { Factors in the rules are not consistent } \\
\text { No confirmatory testing }\end{array}$ \\
\hline Low back pain & CBI health classification system [117] & $\begin{array}{l}\text { System developed theoretically } \\
\text { Empirically tested by the developers } \\
\text { No confirmatory testing }\end{array}$ \\
\hline Low back pain & $\begin{array}{l}\text { Identifying responders to pilates based } \\
\text { exercises [118] }\end{array}$ & $\begin{array}{l}\text { Rule developed empirically } \\
\text { No confirmatory testing }\end{array}$ \\
\hline Neck pain & $\begin{array}{l}\text { Treatment-based classification system for } \\
\text { neck pain }[123,124,128-131,135,137]\end{array}$ & $\begin{array}{l}\text { System developed theoretically } \\
\text { Empirical testing has been promising (case series, pilot and cohort studies) } \\
\text { No evaluation via clinical trial }\end{array}$ \\
\hline Neck pain & $\begin{array}{l}\text { Identifying responders to Thoracic } \\
\text { manipulation }[102,125-127]\end{array}$ & $\begin{array}{l}\text { Rule developed empirically } \\
\text { Unsuccessful evaluation via clinical trial }\end{array}$ \\
\hline Neck pain & $\begin{array}{l}\text { Identifying responders to cervical traction } \\
\text { and exercise }[133,134]\end{array}$ & $\begin{array}{l}\text { Rule developed empirically } \\
\text { No confirmatory testing }\end{array}$ \\
\hline Neck pain & $\begin{array}{l}\text { Identifying responders to home-based } \\
\text { cervical traction [122] }\end{array}$ & $\begin{array}{l}\text { Rule developed empirically } \\
\text { No confirmatory testing }\end{array}$ \\
\hline Neck pain & $\begin{array}{l}\text { Identifying responders to cervical } \\
\text { manipulation }[132,136]\end{array}$ & $\begin{array}{l}\text { Two separate rules developed empirically } \\
\text { Factors in the rules are not consistent } \\
\text { No confirmatory testing }\end{array}$ \\
\hline Neck pain & $\begin{array}{l}\text { Identifying responders to cervical } \\
\text { manipulation physiotherapy or usual care } \\
\text { [138] }\end{array}$ & $\begin{array}{l}\text { Rule developed empirically } \\
\text { No confirmatory testing }\end{array}$ \\
\hline $\begin{array}{l}\text { Patellofemoral } \\
\text { knee pain }\end{array}$ & $\begin{array}{l}\text { Identifying responders to lumbopelvic } \\
\text { manipulation }[141,142]\end{array}$ & $\begin{array}{l}\text { Rule developed empirically } \\
\text { Confirmatory testing in a separate sample was unsuccessful }\end{array}$ \\
\hline
\end{tabular}


Table 6 continued

\begin{tabular}{|c|c|c|}
\hline Condition & Purpose of rule/system & Evaluation status of the rule/system \\
\hline $\begin{array}{l}\text { Patellofemoral } \\
\text { knee pain }\end{array}$ & $\begin{array}{l}\text { Identifying responders to foot orthosis } \\
{[140,146]}\end{array}$ & $\begin{array}{l}\text { Two separate rules developed empirically } \\
\text { Factors in the rules are not consistent } \\
\text { No confirmatory testing }\end{array}$ \\
\hline $\begin{array}{l}\text { Patellofemoral } \\
\text { knee pain }\end{array}$ & $\begin{array}{l}\text { Identifying responders to patellar taping } \\
\text { [143] }\end{array}$ & $\begin{array}{l}\text { Rule developed empirically } \\
\text { No confirmatory testing }\end{array}$ \\
\hline Ankle sprain & $\begin{array}{l}\text { Identifying responders to manipulation and } \\
\text { exercises [148] }\end{array}$ & $\begin{array}{l}\text { Rule developed empirically } \\
\text { No confirmatory testing }\end{array}$ \\
\hline $\begin{array}{l}\text { Lateral } \\
\text { epicondylalgia }\end{array}$ & Classification model for tennis elbow [149] & $\begin{array}{l}\text { Theoretical model description } \\
\text { No empirical testing }\end{array}$ \\
\hline $\begin{array}{l}\text { Lateral } \\
\text { epicondylalgia }\end{array}$ & $\begin{array}{l}\text { Identifying responders to manual therapy and } \\
\text { exercise [147] }\end{array}$ & $\begin{array}{l}\text { Rule developed empirically } \\
\text { No confirmatory testing }\end{array}$ \\
\hline $\begin{array}{l}\text { Thoracolumbar } \\
\text { injury }\end{array}$ & $\begin{array}{l}\text { Classification system for Thoracolumbar } \\
\text { spine injury }[144,145]\end{array}$ & $\begin{array}{l}\text { System developed theoretically } \\
\text { Successful reliability testing } \\
\text { No confirmatory testing }\end{array}$ \\
\hline
\end{tabular}

for patellofemoral pain), but results indicated the rules were not consistent and the rules were formed of different variables.

\section{Discussion}

The number of CDS tools relevant to MSK disorders is small but it appears that this field is rapidly expanding. Results of this scoping review identify that although there are several publications around CDS tools, with the majority (82\%) published since 2006, few correspond to formal and validated tools to help with the management of MSK conditions. Furthermore, the tools, models and classification systems we identified are intended for use by health care providers. One tool, the RSI Quickscan, is intended for use by ergonomists for identifying appropriate management strategies for workers with upper extremity disorders, including job or equipment modifications where appropriate. However, we were unable to locate any decision support systems for human resource managers or other employer agents who develop return-to-work processes and identify appropriate job modifications.

There was a wide range of literature including treatment algorithms/decision-models and several publications related to clinical prediction rules applied in the context of MSK disorders, most commonly low back pain. The included articles were rather diverse and most of this information was exploratory or developmental in nature, particularly with regard to use of research designs that are prone to bias including case series, cross sectional or cohort studies rather than randomized controlled trials, secondary analyses of previous collected data, and lack of replication or testing in validation samples. It appears that research in this area is starting to develop and would benefit from an internationally coordinated effort. Consequently, more studies regarding feasibility, usability, and effectiveness of these tools as well as psychometric testing would benefit the area of CDS tools applied to health care specifically to the area of MSK disorders.

\section{Computer-Based Tools or Questionnaires}

Our review located 3 questionnaires and 5 computer-based tools that were used to select interventions for patients with MSK disorders. Most of these tools were at initial stages of development or validation. However, we were not able to locate or get further information from the authors of 2 tools (DSS and PMA) indicating the developers likely did not pursue further development. The majority of the studies we reviewed were non-experimental in design, focusing on early stages of questionnaire development and testing or focused mainly on process measures, such as clinician ratings of system acceptability and usability. Of the located tools, six had some validity evidence (WATT, SBST, OMPQ, RSI QuickScan, PMA). The tool that appears to have been most evaluated has been the SBST. This tool has been translated into several languages and has demonstrated good discriminative validity when compared with widely accepted questionnaires such as the Roland Morris Disability Questionnaire and Tampa Scale of Kinesiophobia, among others (AUC ranged from 0.79 to 0.91 [155], and $0.75-0.89$ [156]). Although this information is promising, this tool has not been examined through a clinical trial outside the United Kingdom. Thus, the validation studies for these tools overall have not provided strong evidence for use of these tools in clinical or workplace settings. Of note, the OMPQ was not explicitly 
developed as a CDS tool but as a screening/prognostic tool, which may explain the negative results in a validation study [39]. Thus, none of them are ready for widespread implementation in clinical practice since more testing is necessary.

Since the research obtained regarding CDS tools in MSK disorders is at the early stages, information about user preferences regarding the presentation of computer output, including content, formatting (e.g., color, graphics), and length, have not been conducted to date. Similarly, there are no published data concerning technical difficulties (e.g., type and number of system crashes or touch-screen calibration problems) encountered by computer-based CDS tool users. Both issues have important implications for future system refinements and implementation strategies. In addition, there is a lack of information regarding contextual circumstances or the processes used to integrate the CDS into the existing clinical workflow, as well as testing in different populations and settings. Most of the studies found have tested the CDS tools in one single group of patients. In addition, some limitations of the existing CDS tools for treating MSK conditions were lack of integration with computer and/or mobile devices, the reduced use of web-based interfaces, and infrequent use of data directly entered by patients. Some of the tools were even questionnaires administered by paper and pencil, which was also highlighted by the recent review performed by Pombo et al. [157].

Research of the effectiveness of CDS tools to improve patient outcomes is still fairly sparse. Only 3 of these tools (SBST, RSI QuickScan, Continuum of Care) have tested patient outcomes such as patients' recovery, disability, cost, and quality of life. Results from these studies are inconsistent, and more replication with variable settings and population sampling strategies is needed. Other major patient outcomes of interest for policy makers have not been examined, such as health care utilization, health care costs, and communication with health care providers. Similar results have been obtained in early systematic reviews of computerized decision-support systems for chronic pain management in primary care and CDS tools targeted to healthcare professionals, especially for medical conditions [158, 159].

Further validation of these tools with larger samples and with stronger designs are needed. It is necessary that larger randomized controlled trials testing the effectiveness of CDS tools against standard care be performed to determine clearly if these systems are worth being implemented in clinical practice.

\section{Clinical Prediction Rules/Classification Systems}

Clinical Prediction Rules and classification systems that aim to identify which patients would benefit from a specific treatment have attracted the attention of many researchers regarding their effectiveness and validity. Several narrative and two systematic reviews have been conducted [29, 30]. Our scoping review adds to this literature by attempting to inventory all clinical prediction rules developed for a wide variety of MSK conditions and comment on the status of the research in this area. We located 21 clinical prediction rules that have been developed for MSK disorders, however studies evaluating effectiveness of these rules have been inconsistent. Most of the rules lack external validation in different samples using strong methods such as RCTs, but validation studies that have been conducted by separate research groups have largely been unsuccessful. We also found that rules developed for the same treatment for the same condition by different research groups were inconsistent in terms of the clinical variables in the final rules. These results are not surprising based on the results obtained from different systematic reviews focusing on rules in low back pain and the physical therapy area [29, 30, 160]. According to Beneciuk et al. [29] there are several clinical prediction rules in physical therapy that have not been validated in external samples. In addition, recently Patel et al. [161] examined the quality of the validation studies for clinical prediction rules in subjects with back pain. They found that the evidence from randomized trials validating rules for non-specific back pain is weak. These results were also in agreement with those of May et al. [30] Haskin et al. [160] and Patel et al. [161] Thus, based on the current evidence, more widespread use of clinical prediction rules for identifying responders to various interventions in clinical practice is not recommended at this point.

If clinical prediction rules are well designed and validated in appropriate populations, they could have the potential to identify patients most likely to benefit from a particular treatment. This in turn would help improve clinical decisionmaking and practice. However, the current evidence, especially the lack of cross-validation and replication, does not support large-scale implementation of clinical prediction rules to improve disability outcomes [160]. At present, it is unknown if the unsatisfactory performance of rules in clinical trials is because inappropriate rules have been tested, the trials have been poorly designed, underpowered, or simply that it is impossible to develop rules that are fit for all conditions, subjects and settings [29]. Thus more research is needed to elucidate all of these questions.

\section{Treatment Algorithms/Decision-Models}

The literature around treatment algorithms and models was diverse, which made the analysis of these studies challenging. Most of these algorithms or decision models have been developed for determining an appropriate treatment path without formal and rigorous testing. Sample sizes have been relatively small in most cases. The results from 
these studies also are inconsistent. Thus, no clear conclusions extracted from these algorithms or models can be made at this point.

\section{Strengths and Limitations}

This study represents the first attempt to inventory available CDS tools for MSK disorders, and comment on the status of the research literature. Strengths of our project include the involvement of a large international group or researchers and stakeholders with diverse backgrounds who provided input on the project. Additionally, we conducted a very comprehensive literature search (all languages and years since inception of databases) across health, computer science, and management databases with the assistance of research librarians as well as a search of grey literature using validated methods. The methodology used in this project was that of a scoping review, which summarizes the state of the science in a given area, but does not synthesize evidence on specific outcomes (e.g., patient outcomes, cost-effectiveness) across studies. This represents a limitation of the scoping review methodology, but it was appropriate in this case due to the diversity of methods and literature encompassed by the review. Also, scoping review methods do not require detailed critical appraisal and, therefore, study quality likely varied in the articles we identified. Additionally, while we sought to be as comprehensive as possible in our literature search, it is possible that there are other CDS tools under development that we failed to identify. As the various CDS tools are tested in different settings and using consistent methodology, more definitive conclusions about the impact of these tools on clinicians' performance or patients outcomes may be drawn.

\section{Conclusions}

The potential for CDS tools, especially those employing rapidly advancing computer technologies, has sparked great interest among health care providers, case management organizations and funders of care. Our literature review identified 5 computer-based tools, 3 questionnaires, 14 algorithms or decision-models, as well as 21 clinical prediction rules or classification systems. However, currently none of these tools, models or systems appears ready for widespread use in clinical practice to select interventions for patients with MSK disorders. More research is needed examining more advanced levels of validity of existing tools, including impact on patient outcome, or developing new evidence-based CDS tools to help guide clinical and workplace practice for managing patients with MSK disorders.

Acknowledgments The Workers' Compensation Board of Manitoba provided funding for this research.

\section{Compliance with Ethical Standards}

Conflict of interest The authors declare no conflict of interest.

\section{Appendix 1}

See Table 7.

Table 7 Example search strategy

\begin{tabular}{|c|c|}
\hline Searches & Results \\
\hline $\begin{array}{l}\text { Musculoskeletal diseases/or musculoskeletal diseases/or } \\
\text { fasciitis, plantar/or foot deformities, acquired/or heel } \\
\text { spur/or posterior tibial tendon dysfunction/or hand } \\
\text { deformities, acquired/or exp temporomandibular joint } \\
\text { disorders/or bursitis/or joint deformities, acquired/or joint } \\
\text { instability/or joint loose bodies/or patellofemoral pain } \\
\text { syndrome/or shoulder impingement syndrome/or } \\
\text { synovitis/or compartment syndromes/or anterior } \\
\text { compartment syndrome/or ischemic contracture/or } \\
\text { contracture/or dupuytren contracture/or muscle cramp/or } \\
\text { myofascial pain syndromes/or exp tendinopathy/or tennis } \\
\text { elbow/ }\end{array}$ & 75,820 \\
\hline $\begin{array}{l}\text { musculoskeletal pain/or exp back pain/or chronic pain/or } \\
\text { neck pain/or pain, intractable/ }\end{array}$ & 41,30 \\
\hline $\begin{array}{l}\text { exp arm injuries/or exp back injuries/or contusions/or exp } \\
\text { dislocations/or exp fractures, bone/or fractures, cartilage/ } \\
\text { or exp hand injuries/or exp hip injuries/or exp leg } \\
\text { injuries/or exp neck injuries/or occupational injuries/or } \\
\text { soft tissue injuries/or exp spinal injuries/or exp "sprains } \\
\text { and strains"/or exp tendon injuries/ }\end{array}$ & 237,957 \\
\hline $\begin{array}{l}\text { ((Pain* or tear or tears or injur* or sprain* or strain* or } \\
\text { dislocation*) adj (musc* or joint or back or spine or } \\
\text { spinal or neck or cervical or pelvic or hip or rotator cuff } \\
\text { or knee or ankle or elbow or shoulder)).mp. }\end{array}$ & 830 \\
\hline $\begin{array}{l}\text { (carpal tunnel or frozen shoulder or shoulder impingement } \\
\text { or chronic pain or myofascial pain or patellofemoral pain } \\
\text { or regional pain disorder* or whiplash).mp. }\end{array}$ & 39,54 \\
\hline 1 or 2 or 3 or 4 or 5 & 356,444 \\
\hline $\begin{array}{l}\text { (osteoporosis or (diabet* and ulcer*) or fibromyalgia or } \\
\text { ankylosing spondilytis or RA or arthritis or } \\
\text { osteomyelitis).ti. }\end{array}$ & 113,335 \\
\hline exp *Osteoporosis/ & 32,044 \\
\hline exp *Diabetic Foot/ & 4942 \\
\hline exp *Fibromyalgia/ & 5462 \\
\hline exp *Arthritis/ & 165,770 \\
\hline exp *Osteomyelitis/ & 13,996 \\
\hline or/7-12 & 230,601 \\
\hline 6 not 13 & 330,638 \\
\hline Decision Support Systems, Clinical/ & 5200 \\
\hline $\begin{array}{l}\text { decision making, computer-assisted/or decision support } \\
\text { techniques/ }\end{array}$ & 14,671 \\
\hline $\begin{array}{l}\text { decision making/and (model or models or classification or } \\
\text { subgroup* or sub-group* or algorithm*).mp. }\end{array}$ & 12,813 \\
\hline
\end{tabular}


Table 7 continued

\begin{tabular}{|c|c|}
\hline Searches & Result \\
\hline decision support.mp. & 22,1 \\
\hline clinical prediction rule*.mp. & \\
\hline decision tree*.mp. & 11,49 \\
\hline decision system*.tw. & 1 \\
\hline treatment based classification.tw. & \\
\hline knowledge-base*.tw. & 910 \\
\hline treatment rule*.tw. & \\
\hline treatment selection.tw. & 16 \\
\hline targeted treatment*.tw. & 23 \\
\hline (treatment algorithm* or management algorithm*).tw. & 44 \\
\hline $\begin{array}{l}\text { (orebro adj4 (musculoskeletal or questionnaire* or } \\
\text { pain*)).tw. }\end{array}$ & \\
\hline STarT Back.tw. & \\
\hline Acute Low Back Pain Screening.tw. & \\
\hline $\begin{array}{l}\text { ((support* or guide or aid* or rule* or tool*) adj4 } \\
\text { decision).tw. }\end{array}$ & 20,3 \\
\hline active knowledge system*.tw. & \\
\hline inference engine*.tw. & \\
\hline rule based system*.tw. & \\
\hline $\begin{array}{l}\text { artificial intelligence/or expert systems/or "neural networks } \\
\text { (computer)"/or support vector machines/or knowledge } \\
\text { bases/or medical informatics computing/or exp pattern } \\
\text { recognition, automated/ }\end{array}$ & 49,2 \\
\hline (machine learning or artificial intelligence).tw. & 71 \\
\hline connectionist expert system*.tw. & \\
\hline careflow system*.tw. & \\
\hline or/15-37 & 119,83 \\
\hline 14 and 39 & 189 \\
\hline limit 40 to animals & \\
\hline 40 not 41 & 185 \\
\hline limit 42 to "all child ( $0-18$ years)" & \\
\hline limit 43 to "all adult (19 plus years)" & 26 \\
\hline 42 not (43 not 44$)$ & 17 \\
\hline
\end{tabular}

Ovid MEDLINE(R) In-Process \& Other Non-Indexed Citations, Ovid MEDLINE(R) Daily and Ovid MEDLINE(R) 1946 to Dec 10, 2013

Search History (45 searches) (close)

\section{Appendix 2}

Table 8 Definitions of psychometric properties

\begin{tabular}{lll}
\hline $\begin{array}{l}\text { Psychometric } \\
\text { property }\end{array}$ & Definition & Criteria for scoring the \\
& psychometric properties \\
& as accomplished \\
& (adapted from Terwee \\
& et al. [31]) \\
\hline
\end{tabular}

\begin{tabular}{cl}
\hline $\begin{array}{c}\text { Internal } \\
\text { consistency }\end{array}$ & $\begin{array}{c}\text { The extent to which } \\
\text { items in a (sub)scale } \\
\text { are intercorrelated, } \\
\text { thus measuring the } \\
\text { same construct }\end{array}$ \\
$\begin{array}{c}\text { Content } \\
\text { validity }\end{array}$ & $\begin{array}{l}\text { The extent to which the } \\
\text { domain of interest is } \\
\text { comprehensively } \\
\text { sampled by the items } \\
\text { in the questionnaire }\end{array}$
\end{tabular}

Factor analyses performed on adequate sample size AND Cronbach's alpha(s) calculated per dimension AND Cronbach's alpha(s) between 0.70 and 0.95 ;

\section{A clear description is} provided of the measurement aim, the target population, the concepts that are being measured, and the item selection AND target population and (investigators OR experts) were involved in item selection

Criterion
validity

The extent to which scores on a particular questionnaire relate to a gold standard

\section{Construct validity}

The extent to which scores on a particular questionnaire relate to other measures in a manner that is consistent with theoretically derived hypotheses concerning the concepts that are being measured

Reproducibility

a. Agreement The extent to which the scores on repeated measures are close to each other (absolute measurement error)

b. Reliability

Test-retest reliability

The extent of agreement

ICC or Kappa $>0.70$ across two administrations of a test, assuming nothing happened between testings (like treatment or other changeproducing event)
Convincing arguments that agreement is acceptable; that gold standard is "'gold" AND correlation with gold standard $>0.70$;

Specific hypotheses were formulated AND at least $75 \%$ of the results are in accordance with these hypotheses
Convincing arguments

\section{.}

See Table 8. 
Table 8 continued

\begin{tabular}{ccc}
\hline $\begin{array}{l}\text { Psychometric } \\
\text { property }\end{array}$ & Definition & $\begin{array}{l}\text { Criteria for scoring the } \\
\text { psychometric properties } \\
\text { as accomplished } \\
\text { (adapted from Terwee } \\
\text { et al. [31]) }\end{array}$ \\
\hline $\begin{array}{c}\text { Inter-rater } \\
\text { reliability }\end{array}$ & $\begin{array}{l}\text { The extent of agreement } \\
\text { among two or more } \\
\text { raters at a single testing } \\
\text { session. Introduces an } \\
\text { additional source of } \\
\text { unreliability (the rater) } \\
\text { to the test unreliability } \\
\text { found in other domains }\end{array}$ \\
\hline
\end{tabular}

\section{References}

1. Power JD, Perruccio AV, Desmeules M, Lagacé C, Badley EM. Ambulatory physician care for musculoskeletal disorders in Canada. J Rheumatol. 2006;33(1):133-9.

2. Coyte PC, Asche CV, Croxford R, Chan B. The economic cost of musculoskeletal disorders in Canada. Arthritis Care Res. 1998;11(5):315-25.

3. Gagnon CM, Stanos SP, van der Ende G, Rader LR, Norman Harden R. Treatment outcomes for workers compensation patients in a US-Based Interdisciplinary Pain Management Program. Pain Pract. 2013;13(4):282-8.

4. Schaafsma F, Schonstein E, Whelan KM, Ulvestad E, Kenny DT, Verbeek JH. Physical conditioning programs for improving work outcomes in workers with back pain. Cochrane Database Syst Rev. 2010; (1):CD001822.

5. Van Oostrom SH, Driessen MT, De Vet HCW, Franche RL, Schonstein E, Loisel P, Van Mechelen W, Anema JR. Workplace interventions for preventing work disability. Cochrane Database Syst Rev. 2009; (2):CD006955.

6. Karjalainen K, Malmivaara A, van Tulder M, Roine R, Jauhiainen M, Hurri H, Koes B. Multidisciplinary biopsychosocial rehabilitation for subacute low back pain among working age adults. Cochrane Database Syst Rev. (Online : Update Software) 2003; (2):CD002193.

7. Gross DP, Haws C, Niemelainen R. What is the rate of functional improvement during occupational rehabilitation in workers' compensation claimants? J Occup Rehabil. 2012;22(3): 292-300.

8. Hayward RS, El-Hajj M, Voth TK, Deis K. Patterns of use of decision support tools by clinicians. In: AMIA annual symposium proceedings/AMIA symposium, AMIA symposium; 2006, p. 329-33.

9. Haldorsen EMH. The right treatment to the right patient at the right time. Occup Environ Med. 2003;60(4):235-6.

10. Hill JC, Fritz JM. Psychosocial influences on low back pain, disability, and response to treatment. Phys Ther. 2011;91(5): 712-21.

11. Blackmore CC, Mecklenburg RS, Kaplan GS. Effectiveness of clinical decision support in controlling inappropriate imaging. JACR J Am Coll Radiol. 2011;8(1):19-25.

12. Hemens BJ, Holbrook A, Tonkin M, Mackay JA, Weise-Kelly L, Navarro T, Wilczynski NL, Haynes RB. Computerized clinical decision support systems for drug prescribing and management: a decision-maker-researcher partnership systematic review. Implement Sci. 2011;6(1):1-17.
13. Sahota N, Lloyd R, Ramakrishna A, Mackay JA, Prorok JC, Weise-Kelly L, Navarro T, Wilczynski NL, Haynes RB. Computerized clinical decision support systems for acute care management: A decision-maker-researcher partnership systematic review of effects on process of care and patient outcomes. Implement Sci. 2011;6(1):1-14.

14. Souza NM, Sebaldt RJ, Mackay JA, Prorok JC, Weise-Kelly L, Navarro T, Wilczynski NL, Haynes RB. Computerized clinical decision support systems for primary preventive care: a decision-maker-researcher partnership systematic review of effects on process of care and patient outcomes. Implement Sci. 2011;6(1):1-14.

15. Roshanov PS, Misra S, Gerstein HC, Garg AX, Sebaldt RJ, Mackay JA, Weise-Kelly L, Navarro T, Wilczynski NL, Haynes RB. Computerized clinical decision support systems for chronic disease management: a decision-maker-researcher partnership systematic review. Implement Sci. 2011;6(1):1-16.

16. Haynes RB, Wilczynski NL. Effects of computerized clinical decision support systems on practitioner performance and patient outcomes: methods of a decision-maker-researcher partnership systematic review. Implement Sci. 2010;5(1):1-8.

17. Nieuwlaat R, Connolly SJ, Mackay JA, Weise-Kelly L, Navarro T, Wilczynski NL, Haynes RB. Computerized clinical decision support systems for therapeutic drug monitoring and dosing: a decision-maker-researcher partnership systematic review. Implement Sci. 2011;6(1):1-14.

18. Patel S, Brown S, Friede T, Griffiths F, Lord J, Ngunjiri A, Thistlethwaite J, Tysall C, Woolvine M, Underwood M. Study protocol: improving patient choice in treating low back pain (IMPACT-LBP): a randomised controlled trial of a decision support package for use in physical therapy. BMC Musculoskel Disord. 2011;12:1-7.

19. Trafton J, Martins S, Michel M, Lewis E, Wang D, Combs A, Scates N, Tu S, Goldstein MK. Evaluation of the acceptability and usability of a decision support system to encourage safe and effective use of opioid therapy for chronic, noncancer pain by primary care providers. Pain Medicine. 2010;11(4): 575-85.

20. Grimshaw J. A knowledge synthesis chapter. Published Online: Canadian Institute of Health Research (Online). http://www.cihrirsc.gc.ca/e/documents/knowledge_synthesis_chapter_e.pdf.

21. Davis K, Drey N, Gould D. What are scoping studies? A review of the nursing literature. Int J Nurs Stud. 2009;46:1386-400.

22. Poth C, Ross S. Meta-analysis, systematic review, or scoping review? Comparing methodologies in educational research. In: The Canadian Society for the Study of Education Annual Congress; 2009.

23. Arskey H, O'Malley L. Scoping studies: towards a methodological framework. Int J Soc Res Methodol. 2005;8(1):19-32.

24. Levac D, Colquhoun H, O'Brien KK. Scoping studies: advancing the methodology. Implement Sci. 2010;5(1):1-9.

25. Grey Matters: a practical search tool for evidence-based medicine. Canadian Agency for Drugs and Technologies in Health. https://www.cadth.ca/resources/finding-evidence/grey-matterspractical-search-tool-evidence-based-medicine.

26. Young AE, Roessler RT, Wasiak R, McPherson KM, van Poppel MN, Anema JR. A developmental conceptualization of return to work. J Occup Rehabil. 2005;15(4):557-68.

27. International Classification of Function, Disability and Health: ICF. In. Geneva, Switzerland: World Health Organization; 2001.

28. Berlin A, Sorani M, Sim I. A taxonomic description of computer-based clinical decision support systems. J Biomed Inform. 2006;39(6):656-67.

29. Beneciuk JM, Bishop MD, George SZ. Clinical prediction rules for physical therapy interventions: a systematic review. Phys Ther. 2009;89(2):114-24. 
30. May S, Rosedale R. Prescriptive clinical prediction rules in back pain research: a systematic review. J Man Manip Ther. 2009; 17(1):36-45.

31. Terwee CB, Bot SDM, de Boer MR, van der Windt DAWM, Knol DL, Dekker J, Bouter LM, de Vet HCW. Quality criteria were proposed for measurement properties of health status questionnaires. J Clin Epidemiol. 2007;60(1):34-42.

32. Gross DP, Zhang J, Steenstra I, Barnsley S, Haws C, Amell T, McIntosh G, Cooper J, Zaiane O. Development of a computerbased clinical decision support tool for selecting appropriate rehabilitation interventions for injured workers. J Occup Rehabil. 2013;23(4):597-609.

33. Hill JC, Vohora K, Dunn KM, Main CJ, Hay EM. Comparing the STarT back screening tool's subgroup allocation of individual patients with that of independent clinical experts. Clin J Pain. 2010;26(9):783-7.

34. Hill JC, Whitehurst DG, Lewis M, Bryan S, Dunn KM, Foster NE, Konstantinou K, Main CJ, Mason E, Somerville S. Comparison of stratified primary care management for low back pain with current best practice (STarT Back): a randomised controlled trial. Lancet. 2011;378(9802):1560-71.

35. Knab JH, Wallace MS, Wagner RL, Tsoukatos J, Weinger MB. The use of a computer-based decision support system facilitates primary care physicians' management of chronic pain. Anesth Analg. 2001;93(3):712-20.

36. Shaw WS, Reme SE, Pransky G, Woiszwillo MJ, Steenstra IA, Linton SJ. The pain recovery inventory of concerns and expectations: a psychosocial screening instrument to identify intervention needs among patients at elevated risk of back disability. J Occup Environ Med. 2013;55(8):885-94.

37. Stephens B, Gross DP. The influence of a continuum of care model on the rehabilitation of compensation claimants with soft tissue disorders. Spine. 2007;32(25):2898-904.

38. Womack SK, Armstrong TJ. Use of a computerized decision support system for primary and secondary prevention of workrelated MSD disability. J Occup Rehabil. 2005;15(3):313-28.

39. Aravena HI. Utility of the Orebro Musculoskeletal Questionnaire as a Screening and Clinical Decision Support tool in Workers's Compensation Claims Edmonton. Canada: University of Alberta; 2014.

40. Speklé EM, Hoozemans MJ, Blatter BM, Heinrich J, van der Beek AJ, Knol DL, Bongers PM, van Dieën JH. Effectiveness of a questionnaire based intervention programme on the prevalence of arm, shoulder and neck symptoms, risk factors and sick leave in computer workers: a cluster randomised controlled trial in an occupational setting. BMC Musculoskel Disord. 2010;11(1):99.

41. Zhang J, Cao P, Gross D, Zaiane OR. On the application of multi-class classification in physical therapy recommendation. Health Inf Sci Syst Health Inf Sci Syst. 2013;1(1):1-15.

42. Qin Z, Armijo-Olivo S, Woodhouse LJ, Gross DP. An investigation of the validity of the Work Assessment Triage Tool clinical decision support tool for selecting optimal rehabilitation interventions for workers with musculoskeletal injuries. Clin Rehabil. (Epub ahead of print) 2015:0269215515578696.

43. Qin Z, Armijo-Olivo S, Woodhouse L, Gross D. Evaluation of A Clinical Decision Support Tool for Selecting Optimal Rehabilitation Intervention for Injured Workers. Calgary: Education \& Research Archive: University of Alberta; 2014.

44. Schmidt CO, Pfingsten M, Fahland RA, Lindena G, Marnitz U, Pfeifer K, Kohlmann T, Chenot JF. Assessing a risk tailored intervention to prevent disabling low back pain-protocol of a cluster randomized controlled trial. BMC Musculoskel Disord. 2010;11:1-7.

45. Zhang J, Cao P, Gross D, Zaiane OR. On the application of multi-class classification in physical therapy recommendation. Edmonton: University of Alberta; 2012.
46. Zhang J, Gross D, Zaïane OR. On the application of multi-class classification in physical therapy recommendation. In: 17th Pacific-Asia conference on knowledge discovery and data mining, PAKDD 2013. vol. 7867 LNAI. Gold Coast, QLD; 2013, p. 143-54.

47. Hay EM, Dunn KM, Hill JC, Lewis M, Mason EE, Konstantinou K, Sowden G, Somerville S, Vohora K, Whitehurst D. A randomised clinical trial of subgrouping and targeted treatment for low back pain compared with best current care. The STarT Back Trial Study Protocol. BMC Musculoskel Disord. 2008;9(1):58.

48. Main C, Sowden G, Hill J, Watson P, Hay E. Integrating physical and psychological approaches to treatment in low back pain: the development and content of the STarT Back trial's 'high-risk'intervention (StarT Back; ISRCTN 37113406). Physiotherapy. 2012;98(2):110-6.

49. Robinson ME, George SZ. Screening for problematic low back pain: STarT. Pain. 2012;153(11):2159-60.

50. Storheim K. Targeted physiotherapy treatment for low back pain based on clinical risk can improve clinical and economic outcomes when compared with current best practice. J Physiother. 2012;58(1):57.

51. Traeger A, McAuley JH. STarT Back Screening Tool. J Physiother. 2013;59(2):131

52. Speklé EM, Heinrich J, Hoozemans MJ, Blatter BM, van der Beek AJ, van Dieën JH, van Tulder MW. The cost-effectiveness of the RSI QuickScan intervention programme for computer workers: results of an economic evaluation alongside a randomised controlled trial. BMC Musculoskel Disord. 2010;11(1):259.

53. Sowden G, Hill JC, Konstantinou K, Khanna M, Main CJ, Salmon P, Somerville S, Wathall S, Foster NE. Targeted treatment in primary care for low back pain: the treatment system and clinical training programmes used in the IMPaCT Back study (ISRCTN 55174281). Fam Pract. 2012;29:50-62.

54. Rundell SD, Davenport TE, Wagner T. Physical therapist management of acute and chronic low back pain using the World Health Organization's International Classification of Functioning, Disability and Health. Phys Ther. 2009;89(1):82-90.

55. Stanton TR, Fritz JM, Hancock MJ, Latimer J, Maher CG, Wand BM, Parent EC. Evaluation of a treatment-based classification algorithm for low back pain: a cross-sectional study. Phys Ther. 2011;91(4):496-509.

56. Stanton TR, Hancock MJ, Apeldoorn AT, Wand BM, Fritz JM. What characterizes people who have an unclear classification using a treatment-based classification algorithm for low back pain? A cross-sectional study. Phys Ther. 2013;93(3):345-55.

57. Strong J, Large RG, Ashton R, Stewart A. A New Zealand Replication of the IPAM Clustering Model for alow back Patients. Clin J Pain. 1995;11(4):296-306.

58. Widerstrom B, Olofson N, Arvidsson I. Manual therapy and a suggested treatment based classification algorithm in patients with low back pain: a pilot study. J Back Musculoskel Rehabil. 2007;20(2):61-70.

59. Reme SE, Shaw WS, Steenstra IA, Woiszwillo MJ, Pransky G, Linton SJ. Distressed, immobilized, or lacking employer support? A sub-classification of acute work-related low back pain. J Occup Rehabil. 2012;22(4):541-52.

60. Shaw WS, Pransky G, Patterson W, Linton SJ, Winters T. Patient clusters in acute, work-related back pain based on patterns of disability risk factors. J Occup Environ Med. 2007;49(2):185-93.

61. Steenstra IA, Ibrahim SA, Franche R-L, Hogg-Johnson S, Shaw WS, Pransky GS. Validation of a risk factor-based intervention strategy model using data from the readiness for return to work cohort study. J Occup Rehabil. 2010;20(3):394-405.

62. Fitzgerald G, Axe M, Snyder-Mackler L. A decision-making scheme for returning patients to high-level activity with 
nonoperative treatment after anterior cruciate ligament rupture. Knee Surg Sports Traumatol Arthrosc. 2000;8(2):76-82.

63. Hurd WJ, Axe MJ, Snyder-Mackler L. A 10-year prospective trial of a patient management algorithm and screening examination for highly active individuals with anterior cruciate ligament injury: Part 1, outcomes. Am J Sp Med. 2008;36(1):40-7.

64. Sonnabend DH. Treatment of primary anterior shoulder dislocation in patients older than 40 years of age: conservative versus operative. Clin Orthop Relat Res. 1994;304:74-7.

65. Spiegl UJ, Ryf C, Hepp P, Rillmann P. Evaluation of a treatment algorithm for acute traumatic osseous Bankart lesions resulting from first time dislocation of the shoulder with a two year follow-up. BMC Musculoskel Disord. 2013;14(1):305.

66. Kodama N, Imai S, Matsusue Y. A simple method for choosing treatment of distal radius fractures. J Hand Surg. 2013;38(10):1896-905.

67. Wang WT, Olson SL, Campbell AH, Hanten WP, Gleeson PB. Effectiveness of physical therapy for patients with neck pain: an individualized approach using a clinical decision-making algorithm. Am J Phys Med Rehabil. 2003;82(3):203-18.

68. Björklund M, Djupsjöbacka M, Svedmark $\AA$, Häger C. Effects of tailored neck-shoulder pain treatment based on a decision model guided by clinical assessments and standardized functional tests. A study protocol of a randomized controlled trial. BMC Musculoskel Disord. 2012;13(1):75.

69. Study will use hybrid model to create decision support package for conservative treatment of nonspecific low back pain. Lippincott's Bone Joint Newsl. 2011; 17(6):67-8.

70. Shaw WS, Linton SJ, Pransky G. Reducing sickness absence from work due to low back pain: How well do intervention strategies match modifiable risk factors? J Occup Rehabil. 2006;16(4):591-605.

71. Sueoka SS, LaStayo PC. Zone II flexor tendon rehabilitation: a proposed algorithm. J Hand Ther. 2008;21(4):410-3.

72. Tuttle N. Is it reasonable to use an individual patient's progress after treatment as a guide to ongoing clinical reasoning? J Manipulative Physiol Ther. 2009;32(5):396-403.

73. Van Zundert J, Van Kleef M. Low back pain: From algorithm to cost-effectiveness? Pain Pract. 2005;5(3):179-89.

74. Wisneski RJRR. The Pennsylvania Plan II: an algorithm for the management of lumbar degenerative disc disease. Instr Course Lect. 1985;34:17-36.

75. Forseen SE, Corey AS. Clinical decision support and acute low back pain: evidence-based order sets. J Am Coll Radiol. 2012; 9(10):704-12.e704.

76. Murphy DR, Hurwitz EL. A theoretical model for the development of a diagnosis-based clinical decision rule for the management of patients with spinal pain. BMC Musculoskel Disord. 2007;8(1):75.

77. Fritz JM, Brennan GP, Leaman H. Does the evidence for spinal manipulation translate into better outcomes in routine clinical care for patients with occupational low back pain? A casecontrol study. Spine J. 2006;6(3):289-95.

78. Flynn T, Fritz J, Whitman J, Wainner R, Magel J, Rendeiro D, Butler B, Garber M, Allison S. A clinical prediction rule for classifying patients with low back pain who demonstrate shortterm improvement with spinal manipulation. Spine. 2002;27(24):2835-43.

79. Brence J. Should a prescriptive clinical prediction rule drive our decision process in patients with low back pain? SportEX Med. 2013;58:7-8.

80. Chen J, Phillips A, Ramsey M, Schenk R. A case study examining the effectiveness of mechanical diagnosis and therapy in a patient who met the clinical prediction rule for spinal manipulation. J Man Manip Ther. 2009;17(4):216-20.
81. Childs JD. Validation of a clinical prediction rule to identify patients likely to benefit from spinal manipulation: a randomized clinical trial. Pittsburgh: University of Pittsburgh; 2003.

82. Childs JD, Flynn TW, Fritz JM. A perspective for considering the risks and benefits of spinal manipulation in patients with low back pain. Man Ther. 2006;11(4):316-20.

83. Childs JD, Fritz JM, Flynn TW, Irrgang JJ, Johnson KK, Majkowski GR, Delitto A. A clinical prediction rule to identify patients with low back pain most likely to benefit from spinal manipulation: a validation study. Ann Intern Med. 2004;141(12):920-8.

84. Childs JD, Fritz JM, Piva SR, Erhard RE. Clinical decision making in the identification of patients likely to benefit from spinal manipulation: a traditional versus an evidence-based approach. J Orthop Sports Phys Ther. 2003;33(5):259-72.

85. Cleland J, Fritz J, Childs JD, Kulig K, Eberhart S, Davenport T, Magel J, Landel RF. Generalizability of a clinical prediction rule for identifying patients with low back pain who are likely to respond rapidly and dramatically to thrust manipulation. In: 14th annual meeting of the American Academy of Orthopaedic Manual Physical Therapists: 2008; Seattle, Washington; 2008, p. 161-81.

86. Cleland JA, Fritz JM, Kulig K, Davenport TE, Eberhart S, Magel J, Childs JD. Comparison of the effectiveness of three manual physical therapy techniques in a subgroup of patients with low back pain who satisfy a clinical prediction rule: a randomized clinical trial. Spine. 2009;34(25):2720-9.

87. Cleland JA, Fritz JM, Whitman JM, Childs JD, Palmer JA. The use of a lumbar spine manipulation technique by physical therapists in patients who satisfy a clinical prediction rule: a case series. J Orthop Sports Phys Ther. 2006;36(4):209-14.

88. Fritz JM, Childs JD, Flynn TW. Pragmatic application of a clinical prediction rule in primary care to identify patients with low back pain with a good prognosis following a brief spinal manipulation intervention. BMC Fam Pract. 2005;6(1):29.

89. Hallegraeff HJM, Winters JC, de Greef M, Lucas C. Manipulative therapy and clinical prediction criteria in treatment of acute nonspecific low back pain. Percept Mot Skills. 2009;108(1):196-208.

90. Hancock MJ, Maher CG, Latimer J, Herbert RD, McAuley JH. Independent evaluation of a clinical prediction rule for spinal manipulative therapy: a randomised controlled trial. Eur Spine J. 2008;17(7):936-43.

91. Learman K, Showalter C, Cook C. Does the use of a prescriptive clinical prediction rule increase the likelihood of applying inappropriate treatments? A survey using clinical vignettes. Man Ther. 2012;17(6):538-43.

92. Maher C, Childs JD, Cleland JA, Vreeman DJ. Clinical prediction rules. Virginia: American Physical Therapy Association Inc.; 2006. p. 759.

93. May S, Rosedale R. A case of a potential manipulation responder whose back pain resolved with flexion exercises. J Manipulative Physiol Ther. 2007;30(7):539-42.

94. Resch K. Can a spinal manipulation clinical prediction rule improve decision making for patients with low back pain? Focus Altern Complement Ther. 2005;10(4):309-10.

95. Schenk R, Dionne C, Simon C, Johnson R. Effectiveness of mechanical diagnosis and therapy in patients with back pain who meet a clinical prediction rule for spinal manipulation. J Man Manip Ther. 2012;20(1):43-9.

96. Underwood M. A clinical prediction rule predicted outcome in patients with low back pain having spinal manipulation and exercise treatment. Evid Based Med. 2005;10(4):125-125.

97. Werneke MW, Hart D, Oliver D, McGill T, Grigsby D, Ward J, Weinberg J, Oswald W, Cutrone G. Prevalence of classification methods for patients with lumbar impairments using the 
McKenzie syndromes, pain pattern, manipulation, and stabilization clinical prediction rules. J Man Manip Ther. 2010;18(4):197-204.

98. Apeldoorn AT, Ostelo RW, van Helvoirt H, Fritz JM, de Vet $\mathrm{HC}$, van Tulder MW. The cost-effectiveness of a treatmentbased classification system for low back pain: design of a randomised controlled trial and economic evaluation. BMC Musculoskel Disord. 2010;11(1):58.

99. Apeldoorn AT, Ostelo RW, van Helvoirt H, Fritz JM, Knol DL, van Tulder MW, de Vet HC. A randomized controlled trial on the effectiveness of a classification-based system for subacute and chronic low back pain. Spine. 2012;37(16):1347-56.

100. Beneciuk JM, George S, Fritz J. Treatment-based classification subgroups among STarT Back Screening Tool risk categories in patients seeking outpatient physical therapy. In: CSM 2011 Orthopaedic and Sports Physical Therapy Section Programming: 2011; New Orleans, LA; 2011.

101. Brennan GP, Fritz JM, Hunter SJ, Thackeray A, Delitto A, Erhard RE. Identifying subgroups of patients with acute/subacute "nonspecific" low back pain: results of a randomized clinical trial. Spine. 2006;31(6):623-31.

102. Carpenter K, Mintken P. Examination, intervention, and outcomes for 3 patients treated with mechanical traction per the treatment-based classification: a retrospective case series. In: CSM 2009 Orthopaedic and Sports Physical Therapy Section Programming: 2009; Las Vegas, NV; 2009.

103. Delitto A, Erhard RE, Bowling RW. A treatment-based classification approach to low back syndrome: identifying and staging patients for conservative treatment. Phys Ther. 1995;75(6): 470-85.

104. Fritz JM, Cleland JA, Childs JD. Subgrouping patients with low back pain: evolution of a classification approach to physical therapy. J Orthop Sports Phys Ther. 2007;37(6):290-302.

105. George SZ. Characteristics of patients with lower extremity symptoms treated with slump stretching: a case series. J Orthop Sports Phys Ther. 2002;32(8):391-8.

106. Hebert JJ, Koppenhaver SL, Walker BF. Subgrouping patients with low back pain a treatment-based approach to classification. Sports Health Multidiscip Approach. 2011;3(6):534-42.

107. Henry SM, Fritz JM, Trombley AR, Bunn JY. Reliability of a treatment-based classification system for subgrouping people with low back pain. J Orthop Sports Phys Ther. 2012;42(9): 797-805.

108. Parent EC, FJ, Brennan GP, Hunter SJ, Long A. The effect of a workshop on using specific exercises on the outcomes of patients with low back pain and treatment-based classification. In: CSM 2009 Orthopaedic and Sports Physical Therapy Section Programming: 2009; Las Vegas, NV; 2009.

109. Scott DR, MA, Walters J: Use of treatment-based classification groups produces significant outcomes in patients with LBP. In: CSM 2008 Orthopaedic and Sports Physical Therapy Section Programming: 2008; Mashville, Tennessee; 2008.

110. Sions J. Combining mobilization and stabilization clinical prediction rules provide relief for patient with acute exacerbation of chronic low back pain. In: CSM 2009 Orthopaedic and Sports Physical Therapy Section Programming: 2009; Las Vegas; 2009.

111. Widerström B, Olofsson N, Arvidsson I, Harms-Ringdahl K, Larsson UE. Inter-examiner reliability of a proposed decisionmaking treatment based classification system for low back pain patients. Man Ther. 2012;17(2):164-71.

112. Hicks GE, Fritz JM, Delitto A, McGill SM. Preliminary development of a clinical prediction rule for determining which patients with low back pain will respond to a stabilization exercise program. Arch Phys Med Rehabil. 2005;86(9): $1753-62$.
113. May S, Gardiner E, Young S, Klaber-Moffett J. Predictor variables for a positive long-term functional outcome in patients with acute and chronic neck and back pain treated with a McKenzie approach: a secondary analysis. J Man Manip Ther. 2008;16(3):155-60.

114. Fritz JM, Whitman JM, Flynn TW, Wainner RS, Childs JD. Factors related to the inability of individuals with low back pain to improve with a spinal manipulation. Phys Ther. 2004;84(2): 173-90.

115. Cai C, Pua YH, Lim KC. A clinical prediction rule for classifying patients with low back pain who demonstrate short-term improvement with mechanical lumbar traction. Eur Spine J. 2009;18(4):554-61.

116. Fritz JM, Lindsay W, Matheson JW, Brennan GP, Hunter SJ, Moffit SD, Swalberg A, Rodriquez B. Is there a subgroup of patients with low back pain likely to benefit from mechanical traction? Results of a randomized clinical trial and subgrouping analysis. Spine. 2007;32(26):E793-800.

117. Hall H, McIntosh G, Boyle C. Effectiveness of a low back pain classification system. Spine J. 2009;9(8):648-57.

118. Stolze LR, Allison SC, Childs JD. Derivation of a preliminary clinical prediction rule for identifying a subgroup of patients with low back pain likely to benefit from Pilates-based exercise. J Orthop Sports Phys Ther. 2012;42(5):425-36.

119. Laslett M: Clinical prediction rule for rapid pain relief of low back pain following manipulation. NZ J Physiother. 2006; 34(2).

120. Vela LI, Haladay DE, Denegar C. Clinical assessment of lowback-pain treatment outcomes in athletes. J Sport Rehabil. 2011;20(1):74-88.

121. Chaitow L. Clinical prediction rules. J Bodyw Mov Ther. 2010;14(3):207-8.

122. Cai C, Ming G, Ng LY. Development of a clinical prediction rule to identify patients with neck pain who are likely to benefit from home-based mechanical cervical traction. Eur Spine J. 2011;20(6):912-22.

123. Carpenter K, Mintken P, Cleland JA. Evaluation of outcomes in patients with neck pain treated with thoracic spine manipulation and exercise: a case series. NZ J Physiother. 2009;37(2):76.

124. Childs MJD, Fritz JM, Piva SR, Whitman JM. Proposal of a classification system for patients with neck pain. J Orthop Sports Phys Ther. 2004;34(11):686-700.

125. Cleland JA, Childs JD, Fritz JM, Whitman JM, Eberhart SL. Development of a clinical prediction rule for guiding treatment of a subgroup of patients with neck pain: use of thoracic spine manipulation, exercise, and patient education. Phys Ther. 2007;87(1):9-23.

126. Cleland JA, Mintken PE, Carpenter K, Fritz JM, Glynn P, Whitman J, Childs JD. Examination of a clinical prediction rule to identify patients with neck pain likely to benefit from thoracic spine thrust manipulation and a general cervical range of motion exercise: multi-center randomized clinical trial. Phys Ther. 2010;90(9):1239-50.

127. Cleland JA, CJ, Fritz JM, Whitman JM, Eberhart SL, A clinical prediction rule for classifying patients with neck pain who demonstrate short-term improvement with thoracic spine manipulation. In: 12th annual meeting of the American Academy of Orthopaedic Manual Physical Therapists: 2006; Charlotte, NC; 2006, p. 168-87.

128. Farrell KPL, Katherine E. Implementation of a treatment based classification system for neck pain: a pilot study. Orthop Phys Ther Pract. 2011;23(2):91-6.

129. Fritz JM, Brennan GP. Preliminary examination of a proposed treatment-based classification system for patients receiving physical therapy interventions for neck pain. Phys Ther. 2007;87(5):513-24. 
130. Heintz MM, Hegedus EJ. Multimodal management of mechanical neck pain using a treatment based classification system. J Man Manip Ther. 2008;16(4):217-24.

131. O'Hearn M, ML, Gillespie C. Physical therapy outcomes of a treatment-based classification scheme for individuals with neck pain. In: CSM 2009 Orthopaedic and Sports Physical Therapy Section Programming: 2009; Las Vegas, NV; 2009.

132. Puentedura EJ, Cleland JA, Landers MR, Mintken P, Louw A, Fernández-de-las-Peñas C. Development of a clinical prediction rule to identify patients with neck pain likely to benefit from thrust joint manipulation to the cervical spine. J Orthop Sports Phys Ther. 2012;42(7):577-92.

133. Raney NH, Petersen EJ, Smith TA, Cowan JE, Rendeiro DG, Deyle GD, Childs JD. Development of a clinical prediction rule to identify patients with neck pain likely to benefit from cervical traction and exercise. Eur Spine J. 2009;18(3):382-91.

134. Raney NH, PE, Smith TA, Cowan JE, Rendeiro DG, Deyle GD, Childs JD. A clinical prediction rule for classifying patients with neck pain who demonstrate short-term improvement with cervical traction and exercise. In: CSM 2008 Orthopaedic and Sports Physical Therapy Section Programming: 2008; Mashville, Tennessee; 2008.

135. Tamayo A. The use of a clinical prediction rule for diagnosis and treatment based classification system for the treatment of a cervical radiculopathy patient: a case report. Orthop Phys Ther Pract. 2009;21(1):24-30.

136. Tseng Y-L, Wang WT, Chen W-Y, Hou T-J, Chen T-C, Lieu F-K. Predictors for the immediate responders to cervical manipulation in patients with neck pain. Man Ther. 2006;11(4):306-15.

137. Wyatt LH. Commentary on Cleland JA et. al_2007. J Am Chiropract Assoc. 2007; 27.

138. Schellingerhout JM, Verhagen AP. Letter to the Editor concerning "Development of a clinical prediction rule to identify patients with neck pain likely to benefit from cervical traction and exercise" by Raney N et al.(2009) Eur Spine J 18: 382-391. Eur Spine J. 2010;19(5):833-833.

139. Schellingerhout JM, Verhagen AP, Heymans MW, Pool JJM, Vonk F, Koes BW, de Vet HCW. Which subgroups of patients with non-specific neck pain are more likely to benefit from spinal manipulation therapy, physiotherapy, or usual care? Pain. 2008;139(3):670-80.

140. Barton CJ, Menz HB, Crossley KM. Clinical predictors of foot orthoses efficacy in individuals with patellofemoral pain. Med Sci Sports Exerc. 2011;43(9):1603-10.

141. Crowell MS, Wofford NH. Lumbopelvic manipulation in patients with patellofemoral pain syndrome. J Man Manip Ther. 2012;20(3):113-20.

142. Iverson CA, Sutlive TG, Crowell MS, Morrell RL, Perkins MW, Garber MB, Moore JH, Wainner RS. Lumbopelvic manipulation for the treatment of patients with patellofemoral pain syndrome: development of a clinical prediction rule. J Orthop Sports Phys Ther. 2008;38(6):297-312.

143. Lesher JD, Sutlive TG, Miller GA, Chine NJ, Garber MB, Wainner RS. Development of a clinical prediction rule for classifying patients with patellofemoral pain syndrome who respond to patellar taping. J Orthop Sports Phys Ther. 2006;36(11):854-66.

144. Vaccaro AR, Lehman RA Jr, Hurlbert RJ, Anderson PA, Harris M, Hedlund R, Harrop J, Dvorak M, Wood K, Fehlings MG. A new classification of thoracolumbar injuries: the importance of injury morphology, the integrity of the posterior ligamentous complex, and neurologic status. Spine. 2005;30(20):2325-33.

145. Vaccaro AR, Oner C, Kepler CK, Dvorak M, Schnake K, Bellabarba C, Reinhold M, Aarabi B, Kandziora F, Chapman J. AOSpine thoracolumbar spine injury classification system: fracture description, neurological status, and key modifiers. Spine. 2013;38(23):2028-37.

146. Vicenzino B, Collins N, Cleland J, McPoil T. A clinical prediction rule for identifying patients with patellofemoral pain who are likely to benefit from foot orthoses: a preliminary determination. Br J Sports Med. 2010;44(12):862-6.

147. Vicenzino B, Smith D, Cleland J, Bisset L. Development of a clinical prediction rule to identify initial responders to mobilisation with movement and exercise for lateral epicondylalgia. Man Ther. 2009;14(5):550-4.

148. Whitman JM, Cleland JA, Mintken P, Keirns M, Bieniek ML, Albin SR, Magel J, McPoil TG. Predicting short-term response to thrust and nonthrust manipulation and exercise in patients post inversion ankle sprain. J Orthop Sports Phys Ther. 2009;39(3):188-200.

149. Wixom SM, LaStayo P. A potential classification model for individuals with tennis elbow. J Hand Ther. 2012;25(4):418-21.

150. Flynn T. Clinical prediction rules for the lumbar spine. N Z J Physiother. 2009;37(3):145-145.

151. Miller J. Clinical prediction rules: Time to sacrifice the holy cow of specificity? J Man Manip Ther. 2007;15(2):123-4.

152. Murphy DR, Hurwitz EL. Application of a diagnosis-based clinical decision guide in patients with low back pain. Chiropr Man Ther. 2011;19(1):1-10.

153. Nee RJ, Coppieters MW. Interpreting research on clinical prediction rules for physiotherapy treatments. Man Ther. 2011;16(2):105-8.

154. Yealy DM, Auble TE. Choosing between clinical prediction rules. New Engl J Med. 2003;349(26):2553.

155. Aebischer B, Hill JC, Hilfiker R, Karstens S. German translation and cross-cultural adaptation of the STarT back screening tool. PLoS ONE. 2015;10(7):1-14.

156. Luan S, Min Y, Li G, Lin C, Li X, Wu S, Ma C, Hill JC. Crosscultural adaptation, reliability, and validity of the chinese version of the STarT back screening tool in patients with low back pain. Spine. 2014;39(16):E974-9.

157. Pombo N, Araújo P, Viana J. Knowledge discovery in clinical decision support systems for pain management: a systematic review. Artif Intell Med. 2014;60(1):1-11.

158. Smith MY, Depue JD, Rini C. Computerized decision-support systems for chronic pain management in primary care. Pain Med. 2007;8(Suppl 3):S155-66.

159. Cresswell K, Majeed A, Bates DW, Sheikh A. Computerised decision support systems for healthcare professionals: an interpretative review. Inform Prim Care. 2012;20(2):115-28.

160. Haskins R, Rivett DA, Osmotherly PG. Clinical prediction rules in the physiotherapy management of low back pain: a systematic review. Man Ther. 2012;17(1):9-21.

161. Patel S, Friede T, Froud R, Evans DW, Underwood M. Systematic review of randomized controlled trials of clinical prediction rules for physical therapy in low back pain. Spine. 2013;38(9):762-9.

162. Hill JC, Dunn KM, Main CJ, Hay EM. Subgrouping low back pain: a comparison of the STarT Back Tool with the Örebro Musculoskeletal Pain Screening Questionnaire. Eur J Pain. 2010;14(1):83-9.

163. Betten C, Sandell C, Hill JC, Gutke A. Cross-cultural adaptation and validation of the Swedish STarT Back Screening Tool. Eur J Physiother. 2015;17(1):29-36.

164. Bruyère O, Demoulin M, Beaudart C, Hill JC, Maquet D, Genevay S, Mahieu G, Reginster JY, Crielaard JM, Demoulin C. Validity and reliability of the French version of the start back screening tool for patients with low back pain. Spine. 2014;39(2):E123-8.

165. Kongsted A, Johannesen E, Leboeuf-Yde C. Feasibility of the STarT back screening tool in chiropractic clinics: a cross- 
sectional study of patients with low back pain. Chiropr Man Ther. 2011;19(1):1-10.

166. Mors $\varnothing$ L, Albert H, Kent P, Manniche C, Hill J. Translation and discriminative validation of the STarT Back Screening Tool into Danish. Eur Spine J. 2011;20(12):2166-73.

167. Gusi N, Del Pozo-Cruz B, Olivares PR, Hernández-Mocholi M, Hill JC. The Spanish version of the "sTarT back screening tool" (SBST) in different subgroups. Aten Prim. 2011;43(7):356-61.

168. Bruyère $O$, Demoulin $M$, Brereton $C$, Humblet $F$, Flynn $D$, Hill JC, Maquet D, Van Beveren J, Reginster JY, Crielaard JM, et al. Translation validation of a new back pain screening questionnaire (the STarT Back Screening Tool) in French. Arch Public Health. 2012;70(1):1-12.

169. Piironen S, Paananen M, Haapea M, Hupli M, Zitting P, Ryynänen K, Takala EP, Korniloff K, Hill JC, Häkkinen A et al: Transcultural adaption and psychometric properties of the STarT
Back Screening Tool among Finnish low back pain patients. Eur Spine J. 2015; 1-9.

170. Speklé EM, Hoozemans MJM, van der Beek AJ, Blatter BM, Bongers PM, van Dieën JH. Internal consistency, test-retest reliability and concurrent validity of a questionnaire on workrelated exposure related to arm, shoulder and neck symptoms in computer workers. Ergonomics. 2009;52(9):1087-103.

171. Hoozemans MJM, Speklé EM, Van Dieën JH. Concurrent validity of questions on arm, shoulder and neck symptoms of the RSI QuickScan. Int Arch Occup Environ Health. 2013;86(7): 789-98.

172. Speklé EM, Hoozemans MJM, van der Beek AJ, Blatter BM, van Dieën JH. The predictive validity of the RSI QuickScan questionnaire with respect to arm, shoulder and neck symptoms in computer workers. Ergonomics. 2012;55(12):1559-70. 